\title{
A Review of Watt-Level CMOS RF Power Amplifiers
}

Ted Johansson and Jonas Fritzin

\section{Linköping University Post Print}

\section{Tweet}

N.B.: When citing this work, cite the original article.

C2009 IEEE. Personal use of this material is permitted. However, permission to reprint/republish this material for advertising or promotional purposes or for creating new collective works for resale or redistribution to servers or lists, or to reuse any copyrighted component of this work in other works must be obtained from the IEEE.

Ted Johansson and Jonas Fritzin, A Review of Watt-Level CMOS RF Power Amplifiers, 2014, IEEE transactions on microwave theory and techniques, (62), 1, 111-124.

http://dx.doi.org/10.1109/TMTT.2013.2292608

Postprint available at: Linköping University Electronic Press

http://urn.kb.se/resolve?urn=urn:nbn:se:liu:diva-104124 


\title{
A Review of Watt-level CMOS RF power amplifiers
}

\author{
Ted Johansson, Senior Member, IEEE, and Jonas Fritzin, Member, IEEE
}

\begin{abstract}
This paper reviews the design of watt-level integrated CMOS RF power amplifiers (PAs) and state-of-the-art results in the literature. To reach watt-level output power from a single-chip CMOS PA, two main strategies can be identified: use of high supply voltage, and use of matching and power combination. High supply voltage limits are closely related to device design in the fabrication process. However, the maximum operating voltage can be improved by amplifier class selection, circuit solutions, and process modifications or mask changes. High output power can also be reached by the use of on-chip matching and power combination, commonly using on-chip transformers. Reliability often sets the limits for the PA design, and PA degradation mechanisms are reviewed. A compilation of state-of-the-art published results for linear and switched wattlevel PAs, as well as a few fully integrated CMOS PAs, is presented and discussed.
\end{abstract}

Index Terms-CMOS Power Amplifiers (PA), integration, System-on-Chip (SoC).

\section{INTRODUCTION}

\section{A. CMOS for wireless SoC}

$\mathrm{T}$ HE wireless market has experienced a remarkable development and growth since the introduction of the first modern mobile phone systems, with a steady increase in the number of subscribers, new application areas, and higher data rates. Much of these advancements are due to successful highlevel integration of the electronic circuitry in low-cost technologies. To continue this development, we need full integration of the RF, analog, and digital parts that constitutes a modern radio into System-on-Chip (SoC) radios. Only modern CMOS technology has the potential to do this.

CMOS has for a long time been the choice for digital integrated circuits due to its high level of integration, low cost, and constant enhancements in performance. Due to the significant scaling of MOS transistors, the transition frequency has reached well beyond $100 \mathrm{GHz}$ [1] and CMOS technology have become popular in RF applications.

During the last decade, considerable effort has been spent

Manuscript received July 24, 2013.

T. Johansson is with the Division of Electronic Devices, Department of Electrical Engineering, Linköping University, SE-581 83 LINKÖPING, Sweden (phone: +46-70-6270237; fax: +46-13-139282; e-mail: ted@isy.liu.se).

J. Fritzin was with Linköping University, SE-581 83 LINKÖPING, Sweden. He is now with Intel Mobile Communications GmbH, Am Campeon 10-12, DE-85579 NEUBIBERG, Germany (e-mail: jonas.fritzin@intel.com). on researching $\mathrm{Si}$ and CMOS-based RFICs for wireless handheld applications [2]-[5]. The digital baseband circuits have now successfully been integrated in CMOS as well as most of the radio building blocks. To lower the cost and to achieve complete integration of a radio $\mathrm{SoC}$, it is desirable to also integrate the power amplifier (PA) in a single CMOS chip [6]-[10]. Whereas digital circuits benefit from the technology scaling, it is becoming harder for the radio, and especially the PA, to meet requirements on linearity, output power, bandwidth, and efficiency using the low supply voltages that follow from technology scaling. However, the almost-for-free integration of CMOS opens up possibilities for new PA architectures.

For the PA, the path to the fully integrated SoC can be seen as a two-step process. The first step is the stand-alone integrated CMOS PA, using as few external components as possible, fabricated in same technology as the SoC. The first watt-level, fully integrated CMOS PA, with on-chip matching to $50 \Omega$, was published in 2001 [11] using a transformer power combination technique known as distributed active transformers (DAT), and linear PAs blocks. A literature survey of published CMOS PA results [9] shows reported output powers of about $33-34 \mathrm{dBm}(2-2.5 \mathrm{~W})$ at $1-2 \mathrm{GHz}$, about $20 \mathrm{dBm}(0.1 \mathrm{~W})$ at $5-6 \mathrm{GHz}$, and then dropping to below $20 \mathrm{dBm}$ at higher frequency. Section $\mathrm{V}$ in this paper contains more detailed compilations of different architecture watt-level CMOS PAs, but the findings are similar.

The second step is to integrate the PA with the baseband/radio SoC and solve the problems caused by the integration. For communication standards with peak output power less than $30 \mathrm{dBm}$, complete SoCs are common in products today, such as WLAN [12]-[14], shared Bluetooth and WLAN [15], as well as DECT [16]. They include integrated PAs, however most of them are not delivering maximum allowed output power in accordance with the standards.

For cellular handsets, SoCs with full output power are virtually non-existent. However, a $3 \mathrm{G}$ RF transceiver with integrated PA in $65 \mathrm{~nm}$ was recently presented by Intel [17] although detailed specifications have not been released. Standalone 2G handset integrated CMOS-PAs have been commercially available on the market for a number of years [18]-[21]. For 3G (WCDMA) PAs, the groundbreaking work has been done by startup companies, such as Amalfi Semiconductor (now acquired by RFMD), Black Sand Technologies [22], and Javelin Semiconductor (now acquired 
by Avago) [23], [24]. Stand-alone 3G PAs are now available on the market. The first CMOS PA capable of $4 \mathrm{G}$ (LTE) operation at all bands was recently presented [25].

Because of the low breakdown voltages for fast CMOS devices, other technologies, such as GaAs HBT [26], [27], Si bipolar [28], [29], SiGe HBT [30]-[32], and low-voltage LDMOS [33], [34], have so far dominated the small-size PAs. See [35] for CMOS vs. GaAs comparison for mobile phone PAs, and [36] for comparison of different bipolar technologies for similar applications.

As the integration level generally is lower for such technologies, commercial PAs for mobile phones often appear in the form of modules where one or several dies are mounted on an organic or ceramic substrate that also contains the output-matching network [37]-[40]. Considering the low price and maturity of GaAs-based PA modules, the advantages of CMOS-based PA modules are not so clear.

Integration has its own drawbacks. The PA generates excessive heat, can cause cross-talk and disturbance on other chip parts, and occupies large (expensive) chip area because of the integrated passives necessary for matching and power combination.

Existing radio solutions may need to be redesigned to achieve the robustness that the PA integration requires [41]. Between the PA and the antenna, there is a need for additional components, such as additional matching, filters, circulators, and switches [42], [10]. These components may be put together in a separate Front-End-Module (FEM), including the PA [25].

So far, we have mainly discussed PAs for mobile (batteryoperated) operation. On the infrastructure side, there is another potential large market. If the PAs can handle high (peak) output power and thus signals with high peak-to-average power ratio (PAPR), new markets for CMOS PAs will open, such as small (picocell and femtocell) basestation PAs. The newer WLAN standards (e.g. 801.11ac) also utilize high PAPR. This will require the PA to handle high (say 34-40 $\mathrm{dBm})$ peak power. As the average power is about the same level as a mobile phone PAs (about $24 \mathrm{dBm}$, maybe up to 30 $\mathrm{dBm}$ ), so the actual power dissipation will be similar for many applications.

\section{B. Strategies to achieve watt-level CMOS PAs}

For a mobile phone or WLAN PA to deliver $>1 \mathrm{~W}$ peak output power at RF into a load is very demanding. The power $P$ delivered from a PA with a sinusoidal signal, at a peak voltage amplitude $V$, into an ohmic load $R$ can be described as

$$
P=\frac{V^{2}}{2 R} \text {. }
$$

To deliver $1 \mathrm{~W}$ power into a 50-Ohm load, we would need $20 \mathrm{~V}$ peak-to-peak voltage swing, which is much higher than the 1-2 V we could afford over a modern CMOS transistor. For a PA with maximum of $2 \mathrm{~V}$ peak-to-peak voltage swing and a $50-\mathrm{Ohm}$ load, the output power would only be about 10 $\mathrm{mW}(10 \mathrm{dBm})$. As the reduction of geometries and supply voltages continues, generating high output power in CMOS becomes more challenging.

Two main strategies to reach high output power can be identified from (1): increased supply voltage, and reduced load (trading current for voltage). Limits for high supply voltage come mainly from the device design in the fabrication process and the layout, but these can be partially worked around using circuit design-related improvements. For the load, we need to interface to $50 \mathrm{Ohm}$, which means using different load transformation and power combining structures.

\section{Outline of text}

This paper reviews the background and state-of-the-art of integrated CMOS-PA with the focus on high-power output, whilst keeping linearity and efficiency at a reasonable level. The performance of linear class- $\mathrm{A} / \mathrm{B}$, polar modulated, and outphasing PAs will be compared. To be more precise, we are interested in the limits of obtaining high output power (wattlevel) at telecommunication radio frequencies (about $0.5-6$ $\mathrm{GHz}$ ), using device technology mainly available via commercial CMOS foundry technology, to achieve PAs with high integration (single-chip PAs), suitable for SoC. The driving applications are WLAN and cellular, both terminal and infrastructure devices.

In Section II, we review different ways to increase the supply voltage using circuit-related workarounds and using improved device structures. In Section III, we review methods and limitations of load reduction by matching and power combining PA architectures. In Section IV, we will discuss PA reliability concerns. In Section V, state-of-the-art CMOS PAs will be reviewed, and in Section VI we make conclusions and discuss the future of CMOS-PAs.

\section{StRATEgy: SuPPly VOlTAGE}

\section{A. Introduction}

According to (1), output power increases as the square of the supply voltage. Operating the PA at as high supply voltage as possible is therefore desirable. However, modern nmCMOS devices are limited with respect to maximum allowed supply voltage because of low device breakdown voltages (a couple of volts) and reliability (gate oxide, hot electrons) concerns [43], [44]. As most PA classes generate peak voltage higher than the supply voltage (see Section II.B), junction breakdown voltages of two times, up to four times, the supply voltage may be needed. Additional margin may also be needed to achieve robustness during handling or mismatch conditions, which can create high voltage peaks at the PA output.

To stretch the limits of the maximum allowed supply voltages, there are several approaches: (1) use PA classes that reduce the ratio of device breakdown voltage to supply voltage, as will be discussed in Section II.B, (2) use circuit solutions that can handle high supply voltage, Section II.C, and (3) use devices with high breakdown voltages, Section II.D.

\section{B. PA classes and architectures for high output power}

The voltage stress over the internal nodes of the PA is 


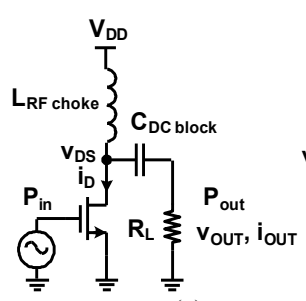

(a)

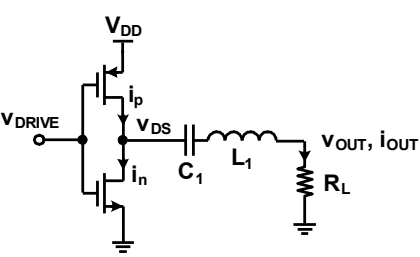

(b)

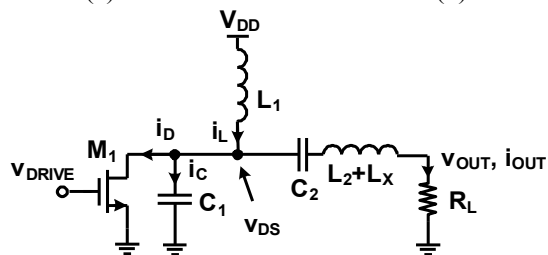

(c)

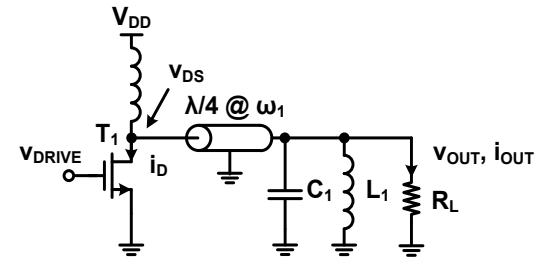

(d)

Fig. 1. Most important PA classes: (a) class-A/B/C (linear), (b) inverterbased class-D (switched), (c) class-E (switched), (d) class-F (switched).

related to the PA class. It is assumed that the reader is familiar with the most common PA classes, otherwise see [45] for a general overview, and [46] for a CMOS oriented overview. Simplified schematics of the most important classes are shown in Fig. 1, and in Table I a selection of amplifier properties for the most important classes is shown. There are also many variants of the basic classes, such as inverted class-E, inverted class-F etc. [45], and classes beyond F, but these mostly lack common definitions, at least for use at RF, and will not further be discussed.

All linear PA classes A, B, and C use the same topology, Fig. 1 (a), but different input bias (gate voltage) levels, which causes the PA to switch off part of the signal cycle. This will cause trade-offs in output power, DC standby current, linearity, and efficiency.

The most popular class, the linear class-AB is not listed in Table I; it is biased somewhere between class A and B and inherits most of the properties of these amplifiers. For simpler modulation signals, it has been a common choice for a long time as it offers a good trade-off between linearity, efficiency, and standby current. The linear PAs will theoretically experience up to two times the supply voltage on their output transistor node during normal operation. For CMOS devices, the maximum allowed drain-to-substrate and drain-to-source voltages must therefore be at least two times the supply voltage. State-of-the-art watt-level linear integrated CMOS PAs will be discussed in Section V (Table II).

By operating the transistors as switches instead of current sources as in linear PAs, amplifiers can achieve theoretical efficiency up to $100 \%$. The inverter-based switched class-D is shown in Fig. 1(b). Basically being an inverter, the class-D amplifier has a peak voltage that will not exceed the supply voltage. Other benefits of class-D PAs are load impedance insensitivity and high bandwidth. However, high-performance inverter-based class-D RF amplifiers require fast p-devices, which have not been available until about the $130 \mathrm{~nm}$ CMOS node. Integrated RF class-D PAs in CMOS have therefore only recently appeared in the literature (Section V, Table IV). The class-D PAs suffer from short-circuit power dissipation, power consumption due to drain capacitance switching, and power losses due to the strong harmonics. All these effects have recently been addressed [47], [48].

The switched class-E has been quite popular in large discrete PAs. It addresses the class-D loss mechanisms due to the parasitic capacitance of the output stage by shaping the drain voltage with reactive load impedance, Fig. 1 (c), in order to decrease the drain voltage to zero as the switch turns on, to minimize the charges stored on the drain capacitance. The maximum theoretical peak voltage is about three and a half times the supply, which is a major drawback. Using a finite inductance instead of an RF-choke (L1 in Fig. 1(c)), the peak voltage can be reduced to two and a half times the supply [49],

TABLE I

A COMPARISON OF THE PROPERTIES OF DIFFERENT PA CLASSES (MANY OF THE NUMBERS DERIVED FROM [46]).

\begin{tabular}{|c|c|c|c|c|c|}
\hline Class & $\begin{array}{l}\text { Maximum drain } \\
\text { efficiency [\%] }\end{array}$ & $\begin{array}{l}\text { Peak drain } \\
\text { voltage }\end{array}$ & $\begin{array}{l}\text { Peak drain } \\
\text { current }^{\mathrm{a}}\end{array}$ & $\begin{array}{c}\text { Maximum output } \\
\text { power }\end{array}$ & $\begin{array}{l}\text { Normalized power } \\
\text { output capability }^{\text {b }}\end{array}$ \\
\hline $\mathrm{A}$ & 50 & $2 * V_{d d}$ & $2 * V_{\mathrm{dd}} / \mathrm{R}$ & $\mathrm{V}_{\mathrm{dd}}^{2} /(2 \mathrm{R})$ & 0.125 \\
\hline $\mathrm{B}$ & 78.5 & $2 * V_{d d}$ & $2 * V_{d d} / R$ & $\mathrm{~V}_{\mathrm{dd}}^{2} /(2 \mathrm{R})$ & 0.125 \\
\hline $\mathrm{C}^{\mathrm{c}}$ & $100^{\mathrm{d}}$ & $2 * V_{d d}$ & $2 * V_{\mathrm{dd}} / \mathrm{R}$ & $\mathrm{V}_{\mathrm{dd}}^{2} /(2 \mathrm{R})$ & 0.125 \\
\hline $\begin{array}{l}\text { inverter-based } \\
\text { switched D }\end{array}$ & 100 & $1 * \mathrm{~V}_{\mathrm{dd}}$ & $\mathrm{V}_{\mathrm{dd}} / \mathrm{R}$ & $\frac{\left(\frac{2}{\pi} V_{d d}\right)^{2}}{2 R}$ & 0.32 \\
\hline switched E & 100 & $3.6 * V_{d d}$ & $1.7^{*} \mathrm{~V}_{\mathrm{dd}} / \mathrm{R}$ & $0.577^{*} \mathrm{~V}_{\mathrm{dd}}^{2} / \mathrm{R}$ & 0.098 \\
\hline switched F & 100 & $8 * \mathrm{~V}_{\mathrm{dd}} / \pi \approx 2.5^{*} \mathrm{~V}_{\mathrm{dd}}$ & $\frac{8}{\pi R} V_{d d}$ & $\frac{\left(\frac{4}{\pi} V_{d d}\right)^{2}}{2 R}$ & 0.16 \\
\hline
\end{tabular}

${ }^{a}$ For the fundamental tone.

${ }^{\mathrm{b}}$ Dimensionless ratio of actual output power to the product of the maximum device voltage and current, [46] p. 497.

${ }^{c}$ Maximum/peak values are not obtained for the same conduction angle $\varphi$.

${ }^{\mathrm{d}}$ Approaches $100 \%$ as the conduction angle $\varphi$ goes to 0 , but so does the output power as well. 


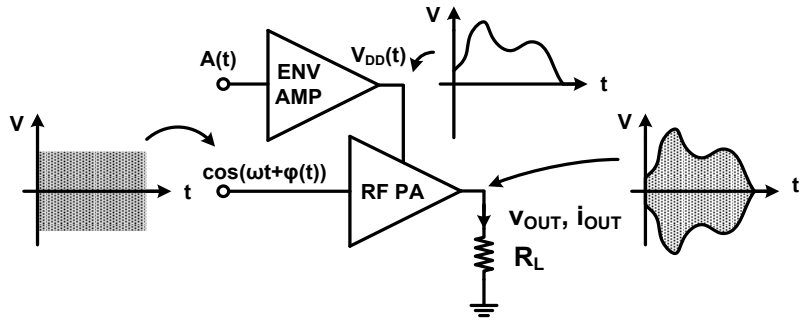

Fig. 2. Polar modulation.

[50]. Higher output power, higher load resistance, or higher efficiency can also be achieved using a finite inductance [50]. State-of-the-art watt-level switched class-E integrated CMOS PAs will be discussed in Section V (Table III).

The related class-F also employs drain voltage waveform shaping to achieve a high efficiency, but uses a $\lambda / 4$ transmission line at the drain and a high-Q tank in parallel with the load resistor. The theoretical peak voltage is slightly above two times the supply, marginally higher than the linear classes. However, to achieve a high efficiency several resonators with a high $\mathrm{Q}$ are needed, requiring additional area. Also, the $\lambda / 4$ transmission line cannot be directly integrated.

One drawback with switched amplifiers is that there is no linear relationship in amplitude between the input signal and the output signal. Additional methods or architectures must therefore be used for amplitude modulation and linearization, which often requires additional blocks and/or redesign of the transmitter architecture, even including the baseband. The different methods can be divided into three groups: supply modulation using polar transmitters [51], [52], outphasing (Chireix [53] and LINC [54]), and pulsewidth modulation [55], [56].

The polar modulation, Fig. 2, combines a non-linear RF PA with an envelope amplifier (ENV AMP) for supply voltage modulation, to achieve a highly efficient linear PA. Most commonly used with class-E PAs, where the drain efficiency does not depend on the supply voltage. The linearity of the amplitude modulator must be good and have a large bandwidth due to the bandwidth expansion of the envelope signal. It is also important to align the amplitude and phase paths (the RF path) in polar transmitter to ensure a clean spectrum despite the bandwidth expansion of the two signals.

A few watt-level polar modulated PAs in CMOS have been demonstrated, mostly using class-E (Section V, Table V), but none is a true single-chip integrated PA.

In the outphasing copt, F an amplitude- and phasemodulated signal, s(t), is detumposed into two constant amplitude signals, s1(t) and $\mathrm{s} 2(\mathrm{t})$, containing the original signal and the quadrature signal, e(t). The two constant amplitude signals are separately amplified by two PAs and then recombined in a power combiner, where the quadrature signals cancel each other as long as the power combiner is linear and the two amplifier paths well balanced. Common ways to realize the power combiner are using a matched combiner with isolation [58] which suffers from low
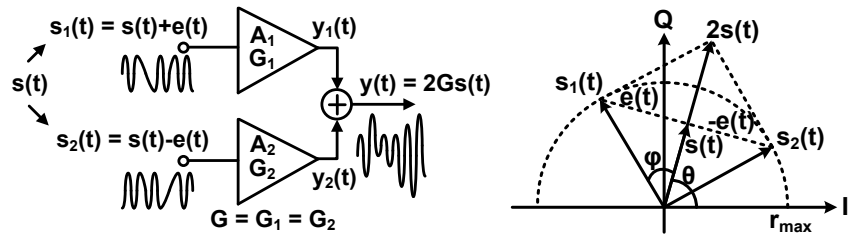

Fig. 3. Outphasing modulation.

efficiency unless the power is recycled [59], on-chip [60]-[62] or off-chip [63] $\lambda / 4$ transmission lines, or connecting the load directly between the two amplifier outputs using a transformer [64].

The outphasing PAs suffers from bandwidth expansion, similar to the polar modulated PAs. To improve linearity and mitigate amplitude and phase mismatches between the signal branches, the supply voltages for the output stages (for amplitude mismatch) and the phases (for amplitude and phase mismatches) should be made adjustable [65].

Watt-level outphasing PAs in CMOS have only been demonstrated using switched class-D architectures (Section V, Table IV). One reason may be that class-E PAs are less suitable for linear operation with non-isolating combiners as the constant envelope operation of the Class-E PA is ruined due to the varying load impedance.

Pulse width modulation (PWM), Fig. 4, is becoming more popular for switched amplifiers. Traditionally used to modulate the input of class-D PAs (sometime referred to as class-S amplifier [45]), but now being used with all types of switched amplifiers [66], [67]. PWM PAs are mainly limited due to the minimum pulse width that the PA can process without pulse swallowing. We have not found any watt-level fully integrated PWM modulated PAs in the literature, but one polar modulated multi-chip is demonstrated in [68] (Section V, Table V).

Most amplifiers can benefit from additional linearization to be able to fulfill requirements on parameters such as adjacent channel power ratio (ACPR) and error-vector magnitude (EVM), while still keeping the output power and efficiency high. Design methods to improve the linearity include additional circuitry to keep the input bias stable for different signal levels, or adjusting the characteristics of individual stages in a multi-stage amplifier. Such improvements are usually classified as Analog Predistortion (APD), and are mostly used with the linear PA-classes [69]. Linearity can also be improved by modifying the amplitude and phase of the baseband signal before the RF modulation, known as Digital

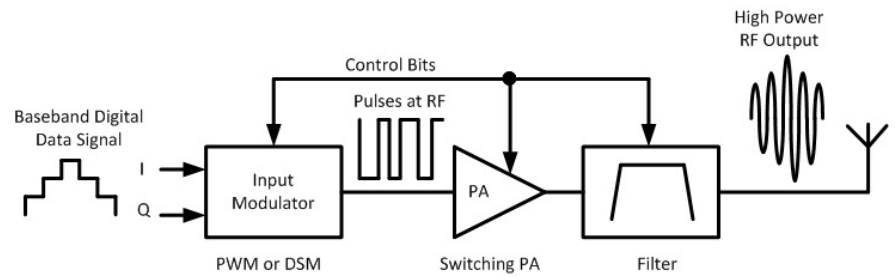

Fig. 4. Pulse-width modulation [57]. 


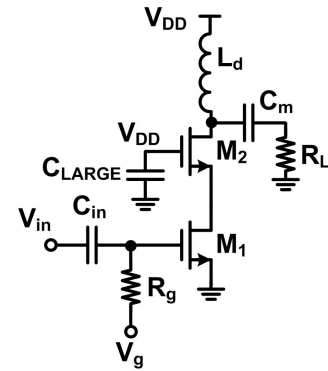

Fig. 5. Cascode

Predistortion (DPD) [70]. This requires system level design of both baseband and RF parts, which increases the complexity of the transmitter.

The maximum efficiency, as listed in Table I, only occurs for the linear classes at some optimum output power level, often close to the $\mathrm{P}-1 \mathrm{~dB}$ point. At lower output power, the efficiency drops rapidly. Efficiency is also reduced in real amplifier implementation because of imperfections and losses in the active and passive components. This is especially true for the switched PA classes, although having high theoretical maximum efficiency (up to $100 \%$ ), the actual numbers quickly drop, as evident from Table III-V in section V.

As modern high data rate signals use advanced modulation techniques where the peak amplitude is 10-12 dB higher than the average signal (PAPR) during transmission, the output power must be reduced, backed-off, typically with the PAPR value to maintain linear amplification [71]. The average efficiency then drops drastically, maybe from more than $50 \%$ to only $5 \%$ at $10 \mathrm{~dB}$ back-off.

There are many methods to improve the efficiency in backoff [72], from simple bias point or supply voltage changes, to architectural level changes. The Doherty amplifier architecture is a very old example of improved efficiency during back-off operation [73]. It has become very popular for high-power base stations PAs [74] but unfortunately less optimal to realize as an integrated amplifier. It consists of two or more linear PAs, and produces high output power with better efficiency over a wider output power range compared to a single linear class- $\mathrm{AB}$ amplifier, while not being so linear. A few integrated Doherty CMOS PAs have been published [75], [76].

The switched amplifiers generally have better back-off efficiency characteristics, as the additional methods needed for amplitude modulation will usually also improve efficiency at lower output power levels.

\section{Circuit solutions}

The most common way to extend the tolerable supply voltage using low-voltage CMOS technology is to use the cascode or stacked transistor structure [77], [78], which in combination with thick-oxide transistors allows operation at higher supply voltage while keeping reliability at a high level. The result is higher output power, higher load, and lower current, which potentially leads to lower losses and higher efficiency. The output impedance is also higher compared to single common-source stage. The common configuration is shown in Fig. 5. The lower transistor, M1, is driven by the

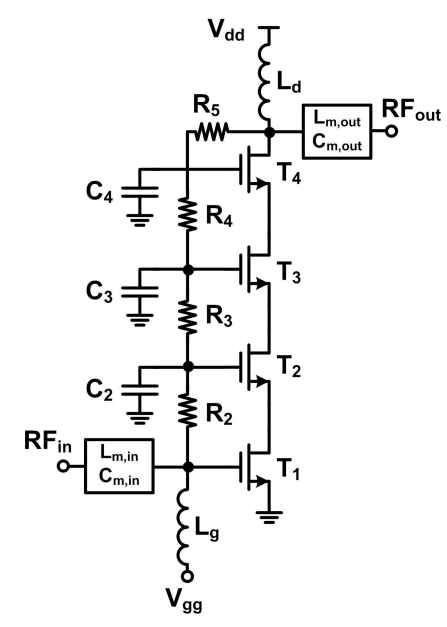

Fig. 6. HiVP (High-Voltage/High-Power) configuration with four devices [81].

input signal in a common-source configuration. The upper transistor, M2, is usually connected to the supply voltage $\mathrm{V}_{\mathrm{dd}}$. M2 operates common gate (gate grounded) at high frequency because of the additional capacitor $\mathrm{C}_{\mathrm{LARGE}}$.

Under large signal operation, the voltage will not be evenly distributed over the devices; the voltage swing on the gatedrain of M2 becomes larger than that of M1 [79]. M1 can therefore be selected for low-voltage operation, e.g. a thinoxide standard transistor with better RF performance/gain, whereas M2 is selected for higher voltage operations, which can be a thick-oxide I/O transistor with longer channel length, typically $0.35-0.6 \mu \mathrm{m}$. As a thick-oxide $\mathrm{I} / \mathrm{O}$ device does not have the same RF performance as a thin-oxide standard device, it will limit the RF performance of the amplifier stage. The width of the cascode transistor must be large enough to not degrade the linearity, but at the same time not too large to have a significant impact on the input or output matching. When the technology is scaled but if PA supply voltage is kept constant, M2 needs to remain essentially the same, so performance of this structure will not improve with technology.

By using self-biasing [80], the supply voltage can be evenly distributed over the two devices. Two similar devices (high performance or high breakdown) can then be used, giving larger design space for voltage swing, reliability, and performance.

In switched PA architectures, the output power, efficiency and gain become a function of the supply voltage. At lower supply voltages, the linearity and efficiency drop because the voltage applied at the gate of the M2 device is insufficient and hence M2 turns off. By biasing the M2 gate using a variable gate supply voltage, this problem can be solved [82].

By connecting several devices in series, stacking them, and biasing them properly, in principle $n$ devices can handle $n$ times the supply voltage, and the load resistor can be made $n^{*} n$ times as high to achieve the same output power [83]. These structures are sometimes known as a HiVP (HighVoltage/High-Power device) configuration, [81], [84], Fig. 6, appearing mostly as non-integrated solutions. Variations of 


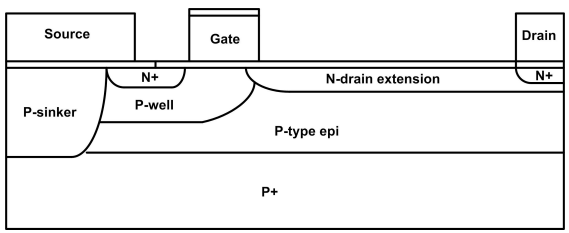

Fig. 7. Conventional LDMOS device

this concept can be found in [85]-[92], and has also been used with bipolar technology [93].

Operating points have to be carefully selected so that the devices operate optimally with good headroom; otherwise there is no performance gain. The cascode's gain is larger; therefore stabilization networks (e.g. an RC-link between gate and drain of M1) may be needed to reduce the risk of oscillations.

\section{High-breakdown devices in standard CMOS processes}

Another way to operate at high supply voltages is to use high-breakdown CMOS-compatible RF devices. Lateral double-diffused MOS (LDMOS) transistors have proven to be successful in base station applications [94], [95]. The advantages of LDMOS for RF PA applications are its thermal stability, high ruggedness, and good linearity characteristics. LDMOS discrete devices typically operate between $24 \mathrm{~V}$ and $50 \mathrm{~V}$ and can deliver up to $50 \mathrm{dBm}$ of output power at $2 \mathrm{GHz}$. LDMOS devices are expected to be used up to $5 \mathrm{GHz}$ [96]. A cross section of a typical discrete device structure is shown in Fig. 7. LDMOS devices have also been used for cellular handset PAs [34], [97].

LDMOS devices can be added to a conventional CMOS process with only a few extra masks and process steps. (We will use the term LDMOS for all these structures, although most of them are not strictly "laterally diffused", rather extended drain structures, EDMOS). An overview, also covering non-RF structures is given in [98]. Early work concentrated on drift-region optimization by the Reduced Surface Field (RESURF) technique [99], requiring process changes and additional masks. For these structures, the onresistance can be minimized while still maintaining high breakdown voltages [100]. Recent examples of process extensions to form CMOS-compatible LDMOS devices can be found in [101]-[103].

LDMOS devices can also be added using layout and design environment changes with no added masks or other process changes. This is attractive to CMOS foundries thus not risking any change of the device parameters of existing CMOS devices. However, optimal performance (breakdown voltage, on-resistance, parasitics) will not be achieved in this way. Examples of LDMOS in CMOS foundry processes can be found in [104]-[109]. A number of CMOS foundries are today offering LDMOS or EDMOS devices into their RF-CMOS processes, but detailed information is sparse or confidential.

Conventionally, PAs are designed with n-devices because of their better RF performance compared to p-devices. However, for certain PA designs, such as switched class-D

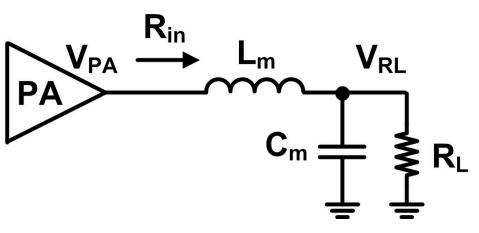

Fig. 8. Common L-match network to increase the power delivered to the load [112].

PAs, there is also a need for high-performance p-type RF devices. Examples of implementations of high-performance LDMOS p-devices can be found in [101], [103], [110] using additional process steps, and [111] without process/mask changes.

To summarize this section, there are several methods to handle high voltages for PAs. Most of the recently published watt-level PAs (Section V) use cascode structures to enable safe operation at reasonable supply voltage.

\section{STRATEGY: LOAD AND POWER COMBINATION}

\section{A. Introduction}

According to (1), the second parameter affecting the output power is the load. Although we could select a load impedance of e.g. $20 \mathrm{Ohm}$ to interface to our PA, it is common to use 50 $\mathrm{Ohm}$ as a reference load between components such as the transceiver, switches, filters, and the antenna. To deliver 33 $\mathrm{dBm}(2 \mathrm{~W})$ into a $50 \mathrm{Ohm}$ load (e.g. the antenna) at $3.3 \mathrm{~V}$ supply voltage, we need a load of $\sim 2.7 \mathrm{Ohm}$. An impedance transformation network is used to transform the smaller load impedance of the PA to $50 \Omega$. As the transformation ratio (50 $\mathrm{Ohm} / \mathrm{Z}_{\text {load }}$ ) increases, the losses in the transformation network itself increase as the network has a finite Q [112].

Simple narrowband transformation networks are usually resonant LC, Fig. 8, or transformer networks. For on-chip elements, especially for large $\mathrm{L}$, the losses can be quite high and therefore LC output matching is often placed outside the chip on the PCB. The L may then consist of part of the PCB conductor pattern, while the $\mathrm{C}$ often is a Surface Mount Device (SMD). The obtained match is rather narrow-band; $100 \mathrm{MHz}$ ( $5 \%$ of the total band) is a typical number for a 2 $\mathrm{GHz}, 27 \mathrm{dBm}$ PA using such a first order LC-network.

The simplest way to reach higher output power, or better matching, is to use differential PA structures, which will be discussed in Section III.B. Transformers can simultaneously be used for impedance transformation, power combining, baluns for differential PAs, and bias feeds. Considerable effort has therefore been made to optimize the structures and layout to integrate them with the PAs. This will be discussed in Section III.C

\section{B. The differential PA}

By increasing the size of the PA output transistor, power is increased accordingly, but the impedance scales equally to lower values and we soon reach a point where the impedance is too small to conveniently be transformed to $50 \mathrm{Ohm}$. The easiest way to further increase the output power for a given 
load is to use a differential structure [113]. The signal is split into two anti-phase paths using a balun or transformer, two similar PA (half-size) blocks are used, and the signal is merged at the PA output using the same technique. If the transmitter architecture is differential, then the signal can be fed directly to/from the PA.

With this structure, we can gain a factor of four in the impedance for a given power, or have (up to) four times the output power for a given load. In practice, there are losses in the splitting and merging elements, but this is still an easy way to achieve higher output power.

The differential structure features a virtual ground, which makes it robust against parasitic inductance from the bondwires and leads to a good cancellation of even harmonics. Most of the switching currents will be internal currents between the two PA blocks, which are easier to handle than high currents to an external ground. In this way, the structure is important for the PA integration, since it reduces the disturbance to other building blocks from large PA signals.

\section{Power combination using on-chip transformers}

Amplifiers operated differentially can be combined using an LC balun [115] and the concept can be extended to $n$ elements, but this strategy is better aimed to increase efficiency as power is increased quadratically with number of elements, but impedance linearly [83].

Instead, the key to really high output power for CMOS PAs is power combination using on-chip transformer structures. Considerable effort has been made to optimize the structures and layout to integrate them with the PAs. For a given transformation ratio, the transformers store less energy in the inductance compared to an LC matching network, resulting in lower loss for a given Q [18].

Transformer combination structures can be categorized as series-combining transformers (voltage mode) or parallelcombining (current mode) transformers, according to their ways of combining at the load [114], [116], Fig. 9. For the series-combining, the secondary coils of $n$ transformers are connected in series, the AC voltages add on the secondary side, generating higher output power. Impedance seen by each amplifier is $n$ times larger compared to being connected directly to the load, which is advantageous for the driver design, and also for reducing the parasitic from the layout on the primary side. Care must be taken to obtain as much symmetry as possible, otherwise mismatch which reduces the maximum output power and efficiency will occur [117], [118].

Aoki et al. [11] used series-combining to achieve the first implementation of a single-chip watt-level CMOS-PA with integrated input and output matching. The series-combining DAT architecture [18] serves as both power combiner and matching network and can provide a solution with high efficiency but occupies a relatively large chip area. By using transformers with different sizes, Javidan et al. [119] were able to shrink the area while still showing good performance. In examples of series power combination [120], [121], 1:1 transformers were used to combine the output of several amplifiers. Since each transformer can be independently

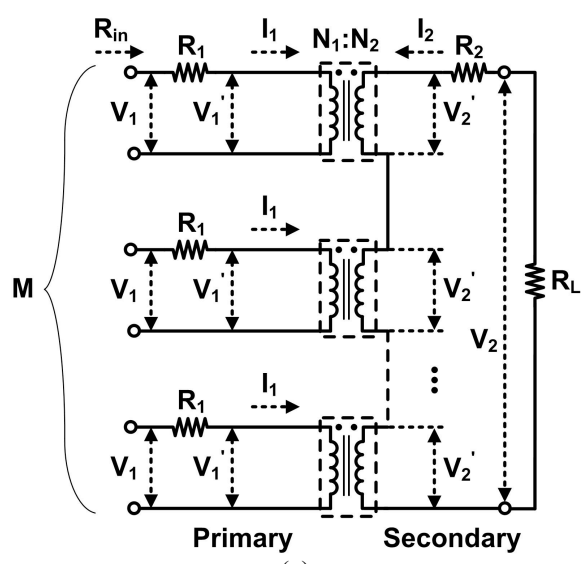

(a)

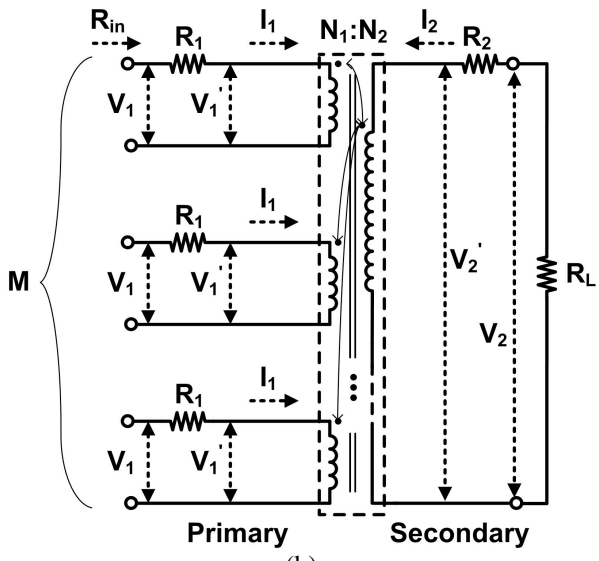

(b)

Fig. 9. Power combining transformers: (a) series, (b) parallel [114].

switched off, it can also be used for power control.

The signal may also be parallel-combined, which results in lower losses on the secondary side and provides better signal symmetry, as demonstrated in [116]. However, the number of turns with this approach becomes larger on the secondary side, increasing the area and lowering the self-resonance frequency. Other examples can be found in [122], [123].

To summarize this section, what has proven to be the key to really high output power for CMOS PAs is power combination using on-chip transformers. Most of the recently published watt-level PAs (Section V) use different variants of on-chip transformer power combination.

\section{PA RELIABILITY CONCERNS}

A key factor behind the success of CMOS devices is the reliable operation of the devices, but this is only achieved at low supply voltages and within specified voltage ranges across the device terminals. This increases the design challenges in circuits with large voltage swings, such as PAs, to achieve the desired output power while still having an acceptable lifetime. The reliability design rules in foundry design manuals do not commonly address the case of large-swing PAs operation, with voltage peaks well above the supply voltage only for a short part of the switching cycle at $\mathrm{GHz}$ frequency. Simulations of internal device node voltages and stress measurements on fabricated devices can be used to explore 
actual limits. The specific circuit configuration and the usecase for the product are important factors for final design considerations [124].

The lifetime of MOS transistors depends mainly on the vertical and lateral electric field in the transistor and across junctions. PA lifetime translates mainly to voltage stress over time (high but short voltage peaks), and only over certain device nodes. Electromigration and thermal issues can often be handled by good layout practices. The actual PA failures will typically be drift in performance parameters, such as reduced output power over time. Catastrophic failures, such as gate oxide breakdowns or junction burnouts, can usually be avoided.

The three main device lifetime-determining mechanisms are (1) gate oxide breakdown, (2) hot-carrier stress, and (3) junction breakdown.

Gate oxide breakdown is catastrophic and must under all situations be avoided. This will set limits for the gate-tosource, gate-to-substrate, and the gate-to-drain voltages. High electrical field over the gate will over time lead to catastrophic breakdown, known as Time-Dependent Dielectric Breakdown (TDDB). A common practice is to keep the maximum voltage drops across the devices below two times the supply voltage, so that the field across the oxide never exceeds the breakdown field of $\sim 1 \mathrm{~V} / \mathrm{nm}$ gate oxide [79], [124]. The impact of oxide RF stress is not as damaging as DC stress [125]. During RF operation, the TDDB is proportional to the RMS value of the electric field over the gate oxide [126].

Hot-carrier stress, or more specific high-voltage gate-todrain stress, will generate high-energy "hot" carriers tunneling through the gate oxide. Some of them will be trapped in the oxide, which will change the threshold voltage and transconductance, degrading the device performance. The hot carriers may also result in avalanche multiplication and surface defects, which will cause reduced carrier mobility in the channel. For devices with $\mathrm{L}>100 \mathrm{~nm}$, hot-carrier stress is most severe when drain-source voltage is high $(>=$ maximum rated supply voltage) and gate-source voltage is around half the drain-source voltage. For devices with $\mathrm{L}<100 \mathrm{~nm}$, maximum stress occurs when gate-source voltage is similar to the drain-source voltage [124].

Junction breakdown, including source-drain punch-through, may not directly be a destructive phenomenon compared to gate oxide breakdown and hot-carrier stress. However, large current and large voltage drop across devices may result in hot carriers and thermal problems, especially if applied for long period of time.

Depending on the circuit configuration, the voltage stress across the device nodes varies. It varies also during the switching cycle and only a small part of the cycle consists of high-stress conditions. Linear class-A/B/C PAs have a significant voltage across the device while conducting current, which creates mainly hot-carrier stress. Switching class-D amplifiers behave like digital inverters with all node voltages smaller than the supply voltage, thus the stress is comparatively low [127].

Class-E switching amplifiers have only a small voltage drop across the transistor when it conducts current, resulting in low hot-carrier stress. However, when a class-E amplifier is in offstate (gate at ground), the drain voltage may peak at values up to 3.5 times the supply voltage, creating a high field at the oxide edge between the gate and the drain [79], [135].

The recommended maximum operating voltage in design manuals to avoid hot carrier degradation is usually based on dc/transient reliability tests. Values may be different for specific PA product use-cases, and stress measurements may be useful. For hot-carrier stress, most of the degradation occurs during the first few hours. In [136] a test was made using a supply voltage of $90 \%$ of the limit for the used technology. The output power of the amplifier decreased in the order of $1 \mathrm{~dB}$ after $70-80$ hours of continuous operation, which was considered to be acceptable. In [124], a test time of 168 hours at elevated supply voltage was considered to cover more than five years of reliable product use for WLAN. The

TABLE II

COMPARISON OF STATE-OF-THE-ART FULLY INTEGRATED RF CLASS-AB LINEAR PAS.

\begin{tabular}{|c|c|c|c|c|c|c|c|c|c|}
\hline Ref. & Year & $\begin{array}{l}\text { P-1dB } \\
{[\mathrm{dBm}]}\end{array}$ & $\begin{array}{c}\text { Psat }^{\mathrm{a}} \\
{[\mathrm{dBm}]}\end{array}$ & $\begin{array}{l}\text { High-power } \\
\text { approach }^{\text {b }}\end{array}$ & $\begin{array}{l}\mathrm{V}_{\mathrm{DD}} \\
{[\mathrm{V}]}\end{array}$ & $\begin{array}{c}\text { PAE } \\
{[\%]}\end{array}$ & $\begin{array}{c}\mathrm{f} \\
{[\mathrm{GHz}]}\end{array}$ & $\begin{array}{c}\text { tech node } \\
{[\mathrm{nm}]}\end{array}$ & $\begin{array}{c}\mathrm{BW} \\
{[\mathrm{GHz}]}\end{array}$ \\
\hline [118] & 2009 & 28.5 & 30.1 & casc/series tr & 3.3 & 33 & 2.4 & 90 & $0.7^{\mathrm{c}}$ \\
\hline [128] & 2012 & & 30.5 & casc/other $\operatorname{tr}$ & 3.4 & 42.1 & 1.95 & 180 & $0.3^{\mathrm{d}}$ \\
\hline$[76]$ & 2012 & & 30.5 & casc/Doherty & 3.3 & 34 & 2.4 & 65 & - \\
\hline [87] & 2010 & & 31 & casc/stacked & 3.6 & 60.5 & 0.85 & 65 & $0.17^{\mathrm{d}}$ \\
\hline [129] & 2011 & 28 & 31 & casc/para tr & 3.3 & 34.8 & 2.5 & 180 & - \\
\hline [130] & 2009 & 27 & 31 & casc/para tr & 3.3 & 27 & 2.4 & 180 & - \\
\hline [131] & 2010 & 27.5 & 31.5 & casc/LC & 3.3 & 25 & 2.45 & 65 & $0.8^{\mathrm{c}}$ \\
\hline [132] & 2006 & & 31.5 & casc/Doherty & 3.3 & 36 & 1.7 & 130 & - \\
\hline [133] & 2010 & & 32 & casc/other tr & 3.3 & 48 & 2.2 & 90 & $>1.4^{\mathrm{d}}$ \\
\hline [90] & 2010 & 30.8 & 32.4 & stacked & 6.5 & 47 & 1.9 & 130 SOI & - \\
\hline [134] & 2013 & 32.8 & & high $\mathrm{V}_{\mathrm{dd}}$ & 3.3 & 52 & 2.4 & $65^{\mathrm{e}}$ & - \\
\hline$[18]$ & 2008 & & 33 & casc/DAT & 3.5 & 45 & 1.9 & 130 & - \\
\hline [116] & 2010 & & 33.5 & casc/para tr & 3.3 & 37.6 & 2.4 & 65 & $2^{c}$ \\
\hline [18] & 2008 & & 35 & casc/DAT & 3.5 & 51 & 0.9 & 130 & - \\
\hline
\end{tabular}


required lifetime should be put in relation to the employed standard and expected use case [137]. A GSM mobile phone used for four hours a day during 18 months corresponds to only 275 hours of continuous PA operation, since 2G GSM has a $12.5 \%$ duty cycle)

\section{STATE-OF-THE-ART PAS}

In this section, state-of-the-art integrated CMOS PAs with peak power greater than $30 \mathrm{dBm}$ are listed and compared. The PAs incorporate most or all of the passive matching and biasing components by utilizing integrated capacitors, inductors, or transformers. A few multi-chip or module PAs have also been included.

Linear PAs are listed in Table II. They provide a more or less complete amplifier on a chip, contrary to the switched
class-D and class-E amplifiers, which need additional circuitry to perform amplitude modulation (section II.B).

As pointed out in Section II.B, class-D amplifiers require fast $p$-devices, which have not been available until about the $130 \mathrm{~nm}$ CMOS node and we have not found any published separate CMOS class-D PA cores with watt-level output, however many class-E PA cores, listed in Table III. (We use the term "PA core" for switched PAs without the additional circuitry for amplitude modulation).

Fully integrated outphasing PAs, including modulation circuitry, are listed in Table IV. They are very recent and based on class-D PA cores.

Polar modulated PAs, including the modulation circuitry, are listed Table V. They are mostly based on class-E cores and no circuit in Table V is a true single-chip integrated PA.

TABLE III

COMPARISON OF STATE-OF-THE-ART INTEGRATED RF CLASS-E SWITCHED PAS (NO AMPLITUDE MODULATOR INCLUDED).

\begin{tabular}{|c|c|c|c|c|c|c|c|c|c|}
\hline Ref. & Year & $\begin{array}{c}\text { Peak } P_{\text {out }} \\
{[\mathrm{dBm}]}\end{array}$ & $\begin{array}{l}\text { High-power } \\
\text { approach }^{\mathrm{a}}\end{array}$ & $\begin{array}{l}V_{D D} \\
{[V]}\end{array}$ & $\begin{array}{l}\mathrm{DE} \\
{[\%]}\end{array}$ & $\begin{array}{l}\text { PAE } \\
{[\%]}\end{array}$ & $\begin{array}{c}\mathrm{f} \\
{[\mathrm{GHz}]}\end{array}$ & $\begin{array}{l}\text { tech node } \\
{[\mathrm{nm}]}\end{array}$ & $\begin{array}{c}\mathrm{BW}^{\mathrm{b}} \\
{[\mathrm{GHz}]}\end{array}$ \\
\hline$[138]$ & 2009 & 30.2 & casc/para tr & 3.3 & & 36.8 & 1.55 & 180 & 0.2 \\
\hline [92] & 2013 & 30.3 & stacked/other tr & 6.35 & & 17.8 & 5.3 & 65 & 1.9 \\
\hline [139] & 2011 & 31 & high $V_{d d}$ & 5 & 77 & 65 & 0.7 & $65^{\mathrm{d}}$ & 0.6 \\
\hline [114] & 2008 & 31.2 & casc/para tr & 3.3 & & 41 & 1.8 & 180 & 0.2 \\
\hline [140] & 2010 & 31.5 & casc & 3.5 & 54 & 51 & 1.8 & 130 & 0.5 \\
\hline [141] & 2007 & 31.5 & casc/DAT & 3.3 & & 41 & 1.8 & 180 & 0.5 \\
\hline [142] & 2007 & 32 & casc/other tr & 3.3 & & 40 & 1.8 & 180 & 0.2 \\
\hline [114] & 2008 & 32 & casc/para tr & 3.3 & & 30 & 1.8 & 180 & 0.2 \\
\hline [143] & 2008 & 32.2 & casc/DAT & 3.3 & 35.6 & & 1.88 & 180 & 0.3 \\
\hline [123] & 2007 & 33 & casc/para tr & 3.3 & & 30 & 1.8 & 180 & 0.3 \\
\hline [11] & 2001 & 33.4 & DAT & 2 & & 31 & 2.4 & 350 & $0.51^{\mathrm{c}}$ \\
\hline [144] & 2009 & 33.8 & casc/para tr & 3.3 & & 50 & 1.8 & 180 & 0.2 \\
\hline [145] & 2007 & 33.5 & casc/DAT & 3.3 & & 41 & 1.8 & 180 & 0.4 \\
\hline [146] & 2009 & 35.3 & high $\mathrm{V}_{\mathrm{dd}}$ & 6 & & 59 & 2 & $65^{\mathrm{d}}$ & - \\
\hline
\end{tabular}

${ }^{a}$ casc $=$ cascode, stacked=more advanced/different than cascode, para tr=parallel transformer combiner, other tr $=$ other type of transformer combiner, DAT $=$ distributed active transformer [11].

${ }^{b} 1 \mathrm{~dB}$ minimum bandwidth estimations from data in papers.

${ }^{\mathrm{c}} 3 \mathrm{~dB}$ bandwidth.

${ }^{c}$ LDMOS device (no process changes).

TABLE IV

COMPARISON OF STATE-OF-THE-ART FULLY INTEGRATED RF OUTPHASING PAS.

\begin{tabular}{ccccccccccc}
\hline \hline Ref. & Year & $\begin{array}{c}\text { Output } \\
\text { PA class }\end{array}$ & $\begin{array}{c}\text { Peak } \mathrm{P}_{\text {out }} \\
{[\mathrm{dBm}]}\end{array}$ & $\begin{array}{c}\text { High-power } \\
\text { approach }^{\mathrm{a}}\end{array}$ & $\begin{array}{c}\mathrm{V}_{\mathrm{DD}} \\
{[\mathrm{V}]}\end{array}$ & $\begin{array}{c}\mathrm{DE} \\
{[\%]}\end{array}$ & $\begin{array}{c}\text { PAE } \\
{[\%]}\end{array}$ & $\begin{array}{c}\mathrm{f} \\
{[\mathrm{GHz}]}\end{array}$ & $\begin{array}{c}\text { tech node } \\
{[\mathrm{nm}]}\end{array}$ & $\begin{array}{c}\mathrm{BW}^{\mathrm{b}} \\
{[\mathrm{GHz}]}\end{array}$ \\
\hline$[147]$ & 2011 & $\mathrm{D}$ & 30.5 & casc/para tr & 6.0 & 29.7 & 26.5 & 1.95 & 65 & 1.60 \\
{$[148]$} & 2012 & $\mathrm{D}$ & 31.5 & casc/para tr & 2.4 & & 27.0 & 2.4 & 45 & 1.70 \\
{$[47]$} & 2011 & $\mathrm{D}$ & 32.0 & casc/para tr & 5.5 & 20.1 & 15.3 & 1.85 & 130 & 0.90 \\
\hline \hline \multicolumn{2}{c}{${ }^{\mathrm{a}}$ casc=cascode, para tr=parallel transformer combiner. } \\
b $3 \mathrm{lB}$ bandwidth.
\end{tabular}

TABLE V

COMPARISON OF STATE-OF-THE-ART INTEGRATED RF POLAR-MODULATED PAS

\begin{tabular}{|c|c|c|c|c|c|c|c|c|c|}
\hline Ref. & Year & $\begin{array}{l}\text { Output } \\
\text { PA class }\end{array}$ & $\begin{array}{c}\text { Peak } P_{\text {out }} \\
{[\mathrm{dBm}]}\end{array}$ & $\begin{array}{l}\text { High-power } \\
\text { approach }^{\mathrm{a}}\end{array}$ & $\begin{array}{l}\mathrm{V}_{\mathrm{DD}} \\
{[\mathrm{V}]}\end{array}$ & $\begin{array}{l}\text { PAE } \\
{[\%]}\end{array}$ & $\begin{array}{c}\mathrm{f} \\
{[\mathrm{GHz}]}\end{array}$ & $\begin{array}{l}\text { tech node } \\
{[\mathrm{nm}]}\end{array}$ & $\begin{array}{c}\mathrm{BW}^{\mathrm{b}} \\
{[\mathrm{GHz}]}\end{array}$ \\
\hline$[68]^{\mathrm{c}}$ & 2012 & $\mathrm{D}$ & 30 & stacked/Guanella & 3.3 & 40.6 & 0.75 & 150 & 0.2 \\
\hline$[21]^{\mathrm{d}}$ & 2009 & $\mathrm{E}$ & 32.5 & casc/para tr & 3.4 & 52 & 1.8 & 180 & 0.2 \\
\hline$[149]^{\mathrm{b}}$ & 2012 & $\mathrm{E}$ & $33^{\mathrm{e}}$ & casc & 3.5 & 34 & 1.8 & 180 & - \\
\hline$[21]^{\mathrm{d}}$ & 2009 & $\mathrm{E}$ & 34.5 & casc/para tr & 3.4 & 55 & 0.9 & 180 & 0.2 \\
\hline$[19]^{\mathrm{f}}$ & 2011 & $\mathrm{E}$ & 34.5 & casc/para tr & $3.0-4.2$ & 55 & 0.9 & 180 & - \\
\hline
\end{tabular}

${ }^{a}$ casc $=$ cascode, stacked=more advanced/different than cascode, Guanella = Guenella reverse balun, para tr=parallel transformer combiner.

${ }^{\mathrm{b}} 1 \mathrm{~dB}$ minimum bandwidth estimations from data in papers.

${ }^{\mathrm{c}}$ Multi-chip. PWM modulated.

${ }^{\mathrm{d}}$ Module.

${ }^{\text {e }}$ Estimated (26 dBm av., $7.5 \mathrm{~dB}$ PAPR, low EVM).

${ }^{\mathrm{f}}$ Output parallel transformers on separate low-loss substrate. 
From the tables, we can observe that there are many examples of CMOS class-AB PAs with saturated output power larger than $1 \mathrm{~W}$ at 1-2.5 GHz. Fully integrated switched PAs with amplitude modulation only have been demonstrated using class-D cores in outphasing architectures.

To gain more insight on how to reach watt-level output power with actual integrated PAs, in the Tables are indicated the different approaches used to achieve high output power. From this, we make the following observations:

(1) The PA should be operated at as high supply voltage as possible. This is achieved using cascode or stacked structures. Almost all of the surveyed PAs, in different classes, are designed in this way. For linear class $\mathrm{A} / \mathrm{B} / \mathrm{C}$ and switched class-E with peak switching voltages of 2-3.5 times $\mathrm{V}_{\mathrm{dd}}$, the PA can be operated reliable at the higher supply voltage (3.3 V) usually available in the system. For the switched class-D, with no overvoltage, cascodes make it possible to operate the PA at increased supply voltage with low-voltage transistors. In this aspect, the class-D architecture may be best suited for use with low supply voltage, e.g. early designs in the new technologies where no additional devices for analog/mixedsignal design yet have been added. But the output power at a given supply voltage is lower for the class-D compared to the linear classes (Table I).

(2) High output power is achieved by using large parallel device structures. As the impedance will get too low to match directly to the ubiquitous $50-\Omega$ output, almost all surveyed PAs use on-chip power combining transformers, with the parallel approach as the dominating solution.

(3) The switching transistor classes need to be used with architectures that provide output power modulation. Although the class-E switched PAs have drawn much research interest lately with (or at least aimed for) polar modulation, the highest demonstrated output power with CMOS integrated PAs have been achieved using class-D amplifiers and outphasing architecture.

Finally, when studying Table II-V, the reader will notice the spread in peak efficiency for different PAs of the same class. What sets the actual efficiency is a combination of PA class, architecture, device operating point, and ultimately losses, both in the circuit and any external matching network. For multi-stage PAs, the properties of the output stage will dominate. As the results in the tables range from researchlevel device-only raw performance, to complete multi-stage circuits with high degree of integration, there is a natural spread in the performance parameters.

\section{CONCLUSIONS AND FUTURE PROSPECT}

This paper has presented a review and state-of-the-art compilation of watt-level integrated CMOS power amplifiers.

Two strategies to reach watt-level output have been identified: the use of high supply voltage, and the use of matching/power combination (high current). When using foundry CMOS processes with few special options for RF and PA design, the designer needs to combine several features to reach watt-level output power.
Stand-alone CMOS-PAs that compete with today's GaAsbased PA modules are less attractive in our view, although they probably can find a niche for low-cost products. The long-term driving force for the integrated PA, or even "the Holy Grail of the RF CMOS quest" [6], is the full integration of digital, analog, radio and PA into a SoC single-chip radio in CMOS.

Watt-level stand-alone linear PAs both for $2 \mathrm{G}$ and $3 \mathrm{G}$ cellular are (almost) off-the-shelf technology today. Although much research has been done in this area during the last decade, fully integrated switched PAs (with potentially higher efficiency) have only appeared quite recently (Table IV). The outphasing architecture using class-D PA core has not widely been accepted as a good solution. For the popular class-Ebased PA using variants of polar modulation/envelope tracking, we have not found any publications of fully integrated PAs; the design of an integrated modulator with high bandwidth and low losses in CMOS appears to be the weak point.

Watt-level integrated RF-PAs are achievable but it will take some more years before we see demonstrations that can be completely integrated with the CMOS transceiver. There is still room for novel architectures that can utilize the large number of transistors available in CMOS almost for free, but also handle the limitations from low supply voltage and lossy substrate and passives, to achieve the ultimate goal of the fully integrated CMOS transceiver.

\section{ACKNOWLEDGEMENT}

The authors would like to acknowledge Duncan Platt and Michael Salter for value comments on the manuscript.

\section{REFERENCES}

[1] "International Technology Roadmap for Semiconductors (ITRS), 2011 Edition, Radio Frequency and Analog/Mixed-Signal Technologies for Wireless Communications," 2011. [Online]. Available: http://www.itrs.net/. [Accessed: May-2013].

[2] H. S. Bennett, R. Brederlow, J. C. Costa, P. E. Cottrell, W. M. Huang, A. A. Immorlica, J. E. Mueller, M. Racanelli, H. Shichijo, C. E. Weitzel, and B. Zhao, "Device and Technology Evolution for Si-Based RF Integrated Circuits," IEEE Trans. Electron Devices, vol. 52, no. 7, pp. 1235-1258, Jul. 2005.

[3] L. E. Larson, "Silicon technology tradeoffs for radio-frequency/mixedsignal 'systems-on-a-chip'," IEEE Trans. Electron Devices, vol. 50, no. 3, pp. 683-699, Mar. 2003.

[4] C. S. Chang, C. P. Chao, J. G. I. Chern, and J. Y. C. Sun, "Advanced CMOS Technology Portfolio for RF IC Applications," IEEE Trans. Electron Devices, vol. 52, no. 7, pp. 1324-1334, Jul. 2005.

[5] A. A. Abidi, "RF CMOS comes of age," IEEE J. Solid-State Circuits, vol. 39, no. 4, pp. 549-561, Apr. 2004.

[6] A. Hajimiri, "Fully integrated RF CMOS power amplifiers - a prelude to full radio integration," Radio Frequency Integrated Circuits Symposium (RFIC), pp. 439-442, 2005.

[7] D. Y. C. Lie, “'RF-SoC': Integration Trends of On-Chip CMOS Power Amplifier: Benefits of External PA versus Integrated PA for Portable Wireless Communications," International Journal of Microwave Science and Technology, no. 3, 2010.

[8] A. Hajimiri, "Next-Generation CMOS RF Power Amplifiers," IEEE Microwave Magazine, vol. 12, no. 1, pp. 38-45, Feb. 2011.

[9] A. M. Niknejad, D. Chowdhury, and J. Chen, "Design of CMOS Power Amplifiers," IEEE Trans. Microwave Theory Techn., vol. 60, no. 6, pp. 1784-1796, Jun. 2012. 
[10] D. W. Nobbe, "Silicon technology status and perspectives for multiband and multi-standard challenges in upcoming RF frontends," Radio and Wireless Symposium (RWS), pp. 191-194, 2008.

[11] I. Aoki, S. D. Kee, D. Rutledge, and A. Hajimiri, "A 2.4-GHz, 2.2-W, 2V fully-integrated CMOS circular-geometry active-transformer power amplifier," Custom Integrated Circuits Conference (CICC), pp. 57-60, 2001.

[12] S. Khorram, H. Darabi, Z. Zhou, Q. Li, B. Marholev, J. Chiu, J. Castaneda, H.-M. Chien, S. B. Anand, S. Wu, M.-A. Pan, R. Roofougaran, H. J. Kim, P. Lettieri, B. Ibrahim, J. J. Rael, L. H. Tran, E. Geronaga, H. Yeh, T. Frost, J. Trachewsky, and A. Rofougaran, "A fully integrated SOC for $802.11 \mathrm{~b}$ in $0.18-\mu \mathrm{m}$ CMOS," IEEE J. Solid-State Circuits, vol. 40, no. 12, pp. 2492-2501, 2005.

[13] S. S. Mehta, D. Weber, M. Terrovitis, K. Onodera, M. P. Mack, B. J. Kaczynski, H. Samavati, S. H. M. Jen, W. W. Si, MeeLan Lee, K. Singh, S. Mendis, P. J. Husted, Ning Zhang, B. McFarland, D. K. Su, T. H. Meng, and B. A. Wooley, "An 802.11g WLAN SoC," IEEE J. SolidState Circuits, vol. 40, no. 12, pp. 2483-2491, Dec. 2005.

[14] A. A. Kidwai, A. Nazimov, Y. Eilat, and O. B. Degani, "Fully integrated $23 \mathrm{dBm}$ transmit chain with on-chip power amplifier and balun for 802.11a application in standard 45nm CMOS process," Radio Frequency Integrated Circuits Symposium (RFIC), pp. 273-276, 2009.

[15] C. P. Lee, A. Behzad, B. Marholev, V. Magoon, I. Bhatti, D. Li, S. Bothra, A. Afsahi, D. Ojo, and R. Roofougaran, "A multistandard, multiband SoC with integrated BT, FM, WLAN radios and integrated power amplifier," International Solid-State Circuits Conference (ISSCC), pp. 454-455, 2010.

[16] C. Grewing, S. van Waasen, B. Bokinge, W. Einerman, A. Emericks, R. Engberg, C. Hedenas, H. Hellberg, M. Hjelm, S. Irmscher, T. Johansson, A. M. Lann, M. Lewis, B. Li, O. Pettersson, W. Simbürger, D. Theil, and R. Thuringer, "CMOS Radio with an Integrated 26dBm Power Amplifier for a Complete System-on-Chip Cordless Phone," Radio Frequency Integrated Circuits Symposium (RFIC), pp. 93-96, 2007.

[17] Intel upgrades $3 G R F$ chip with power amplifiers. [Online]. Available: http://www.eetimes.com/electronics-news/4391339/Intel-upgrades-3GRF-chip-with-power-amplifiers. [Accessed: 16-Dec-2012].

[18] I. Aoki, S. Kee, R. Magoon, R. Aparicio, F. Bohn, J. Zachan, G. Hatcher, D. McClymont, and A. Hajimiri, "A Fully-Integrated QuadBand GSM/GPRS CMOS Power Amplifier," IEEE J. Solid-State Circuits, vol. 43, no. 12, pp. 2747-2758, Dec. 2008.

[19] W. Kim, K. S. Yang, J. Han, J. Chang, and C. H. Lee, "An EDGE/GSM quad-band CMOS power amplifier," International Solid-State Circuits Conference (ISSCC), pp. 430-432, 2011.

[20] J. Browne, "CMOS Power Amp Drives Dual GSM Bands," Microwaves \& $R F$, Mar. 2004.

[21] C. H. Lee, J. J. Chang, K. S. Yang, K. H. An, I. Lee, K. Kim, J. Nam, Y. Kim, and H. Kim, "A highly efficient GSM/GPRS quad-band CMOS PA module," Radio Frequency Integrated Circuits Symposium (RFIC), pp. 229-232, 2009.

[22] Black Sand Technologies. [Online]. Available: http://blacksand.com. [Accessed: 29-Dec-2012].

[23] Javelin Semiconductor. [Online]. Available: http://www.avagotech.com/pages/en/rf_microwave/amplifiers/linear_po wer/cmos_pa/. [Accessed: Jul-2013].

[24] R. Wagner, "3G Power Amplifiers: Moving from GaAs to CMOS," Microwave Journal, pp. 44-48, Apr. 2012.

[25] P. Carson and S. Brown, "Less is More: The New Mobile RF FrontEnd," Microwave Journal, vol. 56, no. 6, pp. 24-34, Jun. 2013.

[26] I. J. Bahl, E. L. Griffin, A. E. Geissberger, C. Andricos, and T. F. Brukiewa, "Class-B power MMIC amplifiers with 70 percent poweradded efficiency," IEEE Trans. Microwave Theory Techn., vol. 37, no. 9, pp. 1315-1320, 1989.

[27] O. Berger, "GaAs HBT for power applications," Proc. BCTM, pp. $52-$ $55,2005$.

[28] F. van Rijs, R. Dekker, P. Magnee, R. Vanoppen, B. N. Balm, and L. C. Colussi, "High gain, high efficiency, low voltage, medium power Sibipolar transistor suitable for integration," Radio Frequency Integrated Circuits Symposium (RFIC), pp. 15-18, 1997.

[29] W. Simbürger, H. D. Wohlmuth, P. Weger, and A. Heinz, "A monolithic transformer coupled 5-W silicon power amplifier with 59\% PAE at 0.9 GHz," IEEE J. Solid-State Circuits, vol. 34, no. 12, pp. 1881-1892, Dec. 1999.

[30] B. Sogl, W. Bakalski, M. Zannoth, M. Asam, B. Kapfelsperger, J. Berkner, B. Eisener, W. Osterreicher, E. Rampf, and A. L. Scholtz, "A quad-band GSM/EDGE-compliant SiGe-bipolar power amplifier with
$35.9 \mathrm{dBm} / 32.3 \mathrm{dBm}$ output power at 56\%/44\% PAE in low/high-band," Proc. BCTM, pp. 98-101, 2007.

[31] P. J. Zampardi, "Performance and Modeling of Si and SiGe for Power Amplifiers," Silicon Monolithic Integrated Circuits in RF Systems (SiRF), pp. 13-17, 2007.

[32] H. Hedayati, M. Mobarak, G. Varin, P. Meunier, P. Gamand, E. Sanchez-Sinencio, and K. Entesari, "A 2-GHz Highly Linear Efficient Dual-Mode BiCMOS Power Amplifier Using a Reconfigurable Matching Network," IEEE J. Solid-State Circuits, vol. 47, no. 10, pp. 2385-2404, Oct. 2012.

[33] G. Ma, W. Burger, C. Dragon, and T. Gillenwater, "High efficiency LDMOS power FET for low voltage wireless communications," IEDM Tech Dig, pp. 91-94, 2006.

[34] T. Shimizu, Y. Matsunaga, S. Sakurai, I. Yoshida, and M. Hotta, "A single-chip Si-LDMOS power amplifier for GSM," International SolidState Circuits Conference (ISSCC), pp. 310-600, 2005.

[35] P. J. Zampardi, "Will CMOS amplifiers ever Kick-GaAs?," presented at the Custom Integrated Circuits Conference (CICC), 2010.

[36] K. Nellis and P. J. Zampardi, "A comparison of linear handset power amplifiers in different bipolar technologies," IEEE J. Solid-State Circuits, vol. 39, no. 10, pp. 1746-1754, Oct. 2004.

[37] C. Jolly, R. Keenan, J. Hug, J. Lucek, S. Ou, and G. Bonaguide, "GaAs HBT PA module design for CDMA handsets," presented at the Gallium Arsenide applications symposium (GAAS), 2001.

[38] M. Franco, "Mobile handset power amplifiers," IEEE Microwave Magazine, vol. 10, no. 7, pp. 16-19, Dec. 2009.

[39] P. Hindle, "2010 GaAs Foundry Services Outlook," Microwave Journal, Jun. 2010.

[40] G. Zhang, S. Khesbak, A. Agarwal, and S. Chin, "Evolution of RFIC Handset PAs," IEEE Microwave Magazine, vol. 11, no. 1, pp. 60-69, Feb. 2010.

[41] O. Pettersson, B. Bokinge, C. Grewing, S. van Waasen, W. Einerman, A. Emericks, R. Engberg, C. Hedenas, C. Hellberg, M. Hjelm, S. Irmscher, T. Johansson, A. M. Lann, M. Lewis, and B. Li, "A Wide Range CMOS Tunable Receiver for Cordless Telephone Applications," International Symposium on Integrated Circuits (ISIC), pp. 104-107, 2007.

[42] "RFMD White paper: 3G/4G Multimode Cellular Front End Challenges," rfmd.com, Feb-2009. [Online]. Available: http://www.rfmd.com/cs/documents/WP\%203G4G\%20Multimode $\% 20$ Handset $\% 20$ Challenges\%20Part\%202\%20Archit ecture\%20Discussion.pdf. [Accessed: 29-Dec-2012].

[43] J. Scholvin, D. R. Greenberg, and J. A. del Alamo, "Fundamental Power and Frequency Limits of Deeply-Scaled CMOS for RF Power Applications," presented at the International Electron Device Meeting (IEDM), 2006.

[44] U. Gogineni, J. A. del Alamo, and C. Putnam, "RF power potential of 45 $\mathrm{nm}$ CMOS technology," Silicon Monolithic Integrated Circuits in $R F$ Systems (SiRF), pp. 204-207, 2010.

[45] S. Cripps, "Amplifier classes, A-S," in Handbook of RF and Microwave Power Amplifiers, no. 4, J. L. B. Walker, Ed. Cambridge, UK: Cambridge University Press, 2012, pp. 159-187.

[46] T. H. Lee, The Design of CMOS Radio-Frequency Integrated Circuits, 2nd ed. Cambridge. UK: Cambridge University Press, 2004, pp. 493559 .

[47] J. Fritzin, C. Svensson, and A. Alvandpour, "A $+32 \mathrm{dBm} 1.85 \mathrm{GHz}$ class-D outphasing RF PA in 130nm CMOS for WCDMA/LTE," Proc. ESSCIRC, pp. 127-130, 2011.

[48] J. Fritzin, C. Svensson, and A. Alvandpour, "A Class-D outphasing RF amplifier with harmonic suppression in 90nm CMOS," Proc. ESSCIRC, pp. 310-313, 2010 .

[49] R. Zulinski and J. Steadman, "Class E Power Amplifiers and Frequency Multipliers with finite DC-Feed Inductance," IEEE Trans. Circuits Syst., vol. 34, no. 9, pp. 1074-1087, Sep. 1987.

[50] C. Yoo and Q. Huang, "A common-gate switched 0.9-W class-E power amplifier with $41 \%$ PAE in $0.25-\mu \mathrm{m}$ CMOS," IEEE J. Solid-State Circuits, vol. 36, no. 5, pp. 823-830, May 2001.

[51] L. R. Kahn, "Single-Sideband Transmission by Envelope Elimination and Restoration," Proc. IRE, vol. 40, no. 7, pp. 803-806, Jul. 1952.

[52] E. McCune, "Envelope Tracking or Polar-Which Is It?," IEEE Microwave Magazine, vol. 13, no. 4, pp. 34-56, Jun. 2012.

[53] H. Chireix, "High power outphasing modulation," Proc. IRE, vol. 23, no. 11 , pp. $1370-1392$, Nov. 1935.

[54] D. Cox, "Linear Amplification with Nonlinear Components," IEEE Trans. Communications, vol. 22, no. 12, pp. 1942-1945, Dec. 1974. 
[55] F. H. Raab, "Radio Frequency Pulsewidth Modulation," IEEE Trans. Communications, vol. 21, no. 8, pp. 958-966, Aug. 1973.

[56] J. Walling and D. Allstot, "Pulse-Width Modulated CMOS Power Amplifiers," IEEE Microwave Magazine, vol. 12, no. 1, pp. 52-60, Feb. 2011.

[57] K. Araki and Y. Morishita, "Past, current, and future trend in reconfigurable transceiver research and development," International Workshop on Radio-Frequency Integration Technology (RFIT), pp. $7-$ 12, 2012.

[58] J. Hur, Ockgoo Lee, Chang-Ho Lee, Kyutae Lim, and J. Laskar, "A Multi-Level and Multi-Band Class-D CMOS Power Amplifier for the LINC System in the Cognitive Radio Application," IEEE Microw. Wireless Compon. Lett., vol. 20, no. 6, pp. 352-354.

[59] P. A. Godoy, D. J. Perreault, and J. L. Dawson, "Outphasing Energy Recovery Amplifier With Resistance Compression for Improved Efficiency," IEEE Trans. Microwave Theory Techn., vol. 57, no. 12, pp. 2895-2906.

[60] A. Pham and C. G. Sodini, “A $5.8 \mathrm{GHz}, 47 \%$ efficiency, linear outphase power amplifier with fully integrated power combiner," presented at the Radio Frequency Integrated Circuits (RFIC) Symposium, 2006.

[61] H. Xu, Y. Palaskas, A. Ravi, M. Sajadieh, M. Elmala, and K. Soumyanath, "A $28.1 \mathrm{dBm}$ class-D outphasing power amplifier in $45 \mathrm{~nm}$ LP digital CMOS," Symposium on VLSI Circuits (VLSIC), pp. 206-207, 2009.

[62] S. Hamedi-Hagh and C. A. T. Salama, "CMOS wireless phase-shifted transmitter," IEEE J. Solid-State Circuits, vol. 39, no. 8, pp. 1241-1252, Aug. 2004.

[63] T.-P. Hung, D. K. Choi, L. E. Larson, and P. M. Asbeck, "CMOS Outphasing Class-D Amplifier With Chireix Combiner," IEEE Microw. Wireless Compon. Lett., vol. 17, no. 8, pp. 619-621.

[64] H. Xu, Y. Palaskas, A. Ravi, and K. Soumyanath, "A highly linear $25 \mathrm{dBm}$ outphasing power amplifier in $32 \mathrm{~nm}$ CMOS for WLAN application," Proc. ESSCIRC, pp. 306-309, 2010.

[65] J. Fritzin, Y. Jung, P. N. Landin, P. Handel, M. Enqvist, and A. Alvandpour, "Phase Predistortion of a Class-D Outphasing RF Amplifier in $90 \mathrm{~nm}$ CMOS," IEEE Trans. Circuits Syst. II, vol. 58, no. 10, pp. 642-646, Oct. 2011.

[66] T.-P. Hung, J. Rode, L. E. Larson, and P. M. Asbeck, "Design of HBridge Class-D Power Amplifiers for Digital Pulse Modulation Transmitters," IEEE Trans. Microwave Theory Techn., vol. 55, no. 12, pp. 2845-2855, Dec. 2007

[67] J. S. Walling, H. Lakdawala, Y. Palaskas, A. Ravi, O. B. Degani, K. Soumyanath, and D. J. Allstot, "A Class-E PA With Pulse-Width and Pulse-Position Modulation in $65 \mathrm{~nm}$ CMOS," IEEE J. Solid-State Circuits, vol. 44, no. 6, pp. 1668-1678.

[68] T. Nakatani, J. Rode, D. F. Kimball, L. E. Larson, and P. M. Asbeck, "Digitally-Controlled Polar Transmitter Using a Watt-Class CurrentMode Class-D CMOS Power Amplifier and Guanella Reverse Balun for Handset Applications," IEEE J. Solid-State Circuits, vol. 47, no. 5, pp. 1104-1112, May 2012

[69] P. B. Kenington, High-linearity RF amplifier design. London: Artech House, 2000.

[70] W.-J. Kim, S. P. Stapleton, J. H. Kim, and C. Edelman, "Digital predistortion linearizes wireless power amplifiers," IEEE Microwave Magazine, vol. 6, no. 3, pp. 54-61, 2005.

[71] H. Ochiai, "Power efficiency comparison of OFDM and single-carrier signals," IEEE Vehicular Technology Conference (VTC), pp. 899-903, 2002.

[72] J. Staudinger, "An overview of efficiency enhancements with application to linear handset power amplifiers," Radio Frequency Integrated Circuits Symposium (RFIC), pp. 45-48, 2002.

[73] W. H. Doherty, "A New High Efficiency Power Amplifier for Modulated Waves," Proc. IRE, vol. 24, no. 9, pp. 1163-1182, Sep. 1936.

[74] S. Cripps, RF Power Amplifier for Wireless Communications, 2nd ed. Norwood, MA: Artech House Publishers, 2006.

[75] N. Wongkomet, L. Tee, and P. R. Gray, "A $1.7 \mathrm{GHz} 1.5 \mathrm{~W}$ CMOS RF Doherty Power Amplifier for Wireless Communications," International Solid-State Circuits Conference (ISSCC), pp. 1962-1971, 2006.

[76] K. Onizuka, S. Saigusa, and S. Otaka, "A +30.5 dBm CMOS Doherty power amplifier with reliability enhancement technique," Symposium on VLSI Circuits (VLSIC), pp. 78-79, 2012.

[77] B. Razavi, $R F$ Microelectronics, 2nd ed. Upper Saddle River, NJ: Prentice Hall, 2012, pp. 776-779.
[78] A. J. Annema, G. J. G. M. Geelen, and P. C. de Jong, "5.5-V I/O in a 2.5-V 0.25- $\mathrm{m}$ CMOS technology," IEEE J. Solid-State Circuits, vol. 36, no. 3, Mar. 2001.

[79] A. Mazzanti, L. Larcher, R. Brama, and F. Svelto, "Analysis of Reliability and Power Efficiency in Cascode Class-E PAs," IEEE J. Solid-State Circuits, vol. 41, no. 5, pp. 1222-1229, May 2006.

[80] T. Sowlati and D. M. W. Leenaerts, "A 2.4-GHz 0.18- $\mu \mathrm{m}$ CMOS selfbiased cascode power amplifier," IEEE J. Solid-State Circuits, vol. 38, no. 8, pp. 1318-1324, Aug. 2003.

[81] J. Luger, I. Dettmann, and M. Berroth, "The integrated $2 \mathrm{~W}$ high voltage/high power 0.12 -um RF CMOS power amplifier," 34th European Microwave Conference, pp. 54-56, 2004.

[82] M. Apostolidou, M. P. van der Heijden, D. M. W. Leenaerts, J. Sonsky, A. Heringa, and I. Volokhine, "A $65 \mathrm{~nm}$ CMOS $30 \mathrm{dBm}$ Class-E RF Power Amplifier With 60\% PAE and 40\% PAE at 16 dB Back-Off," IEEE J. Solid-State Circuits, vol. 44, no. 5, pp. 1372-1379, May 2009.

[83] P. Reynaert and M. Steyaert, RF Power Amplifiers for Mobile Communications. Dordrecht, Holland: Springer, 2006, pp. 87-92.

[84] A. K. Ezzeddine and H. C. Huang, "The high voltage/high power FET (HiVP)," Radio Frequency Integrated Circuits Symposium (RFIC), pp. 215-218, 2003.

[85] H. S. Oh, C. S. Kim, H. K. Yu, and C. K. Kim, "A fully-integrated +23$\mathrm{dBm}$ CMOS triple cascode linear power amplifier with inner-parallel power control scheme," presented at the Radio Frequency Integrated Circuits (RFIC) Symposium, 2006.

[86] Lei Wu, I. Dettmann, and M. Berroth, "A 900-MHz 29.5-dBm 0.13-um CMOS HiVP Power Amplifier," IEEE Trans. Microwave Theory Techn., vol. 56, no. 9, pp. 2040-2045, Sep. 2008

[87] S. Leuschner, S. Pinarello, U. Hodel, J. E. Mueller, and H. Klar, "A 31$\mathrm{dBm}$, high ruggedness power amplifier in 65-nm standard CMOS with high-efficiency stacked-cascode stages," Radio Frequency Integrated Circuits Symposium (RFIC), pp. 395-398, 2010.

[88] A. K. Ezzeddine, H. C. Huang, and J. L. Singer, "UHiFET - A new highfrequency High-Voltage device," presented at the International Microwave Symposium (MTT-S), 2011.

[89] M. Fathi, D. K. Su, and B. A. Wooley, "A stacked 6.5-GHz 29.6-dBm power amplifier in standard 65-nm CMOS," presented at the Custom Integrated Circuits Conference (CICC), 2010.

[90] S. Pornpromlikit, J. Jeong, C. D. Presti, A. Scuderi, and P. M. Asbeck, "A Watt-Level Stacked-FET Linear Power Amplifier in Silicon-onInsulator CMOS," IEEE Trans. Microwave Theory Techn., vol. 58, no. 1, pp. 57-64, Jan. 2010

[91] D. Fritsche, R. Wolf, and F. Ellinger, "Analysis and Design of a Stacked Power Amplifier With Very High Bandwidth," IEEE Trans. Microwave Theory Techn., vol. 60, no. 10, pp. 3223-3231, Oct. 2012.

[92] M. Fathi, D. K. Su, and B. A. Wooley, "A $30.3 \mathrm{dBm} 1.9 \mathrm{GHz}-$ bandwidth $2 \times 4$-array stacked $5.3 \mathrm{GHz}$ CMOS power amplifier," International Solid-State Circuits Conference (ISSCC), 2013.

[93] T. J. Farmer, A. Darwish, and M. E. Zaghloul, "A 2.4 GHz SiGe HBT High Voltage/High Power Amplifier," IEEE Microw. Wireless Compon. Lett., vol. 20, no. 5, pp. 286-288, May 2010.

[94] W. Burger and C. P. Dragon, "Silicon LDMOS and VDMOS transistors: physics, design, and technology," in Handbook of RF and Microwave Power Amplifiers, J. L. B. Walker, Ed. Cambridge. UK: Cambridge University Press, 2012, pp. 1-41.

[95] S. J. C. H. Theeuwen and J. H. Qureshi, "LDMOS Technology for RF Power Amplifiers," IEEE Trans. Microwave Theory Techn., vol. 60, no. 6, pp. 1755-1763, Jun. 2012.

[96] F. van Rijs, "Status and trends of silicon LDMOS base station PA technologies to go beyond $2.5 \mathrm{GHz}$ applications," Radio and Wireless Symposium (RWS), pp. 69-72, 2008.

[97] A. Tombak, D. C. Dening, M. S. Carroll, J. Costa, and E. Spears, "HighEfficiency Cellular Power Amplifiers Based on a Modified LDMOS Process on Bulk Silicon and Silicon-On-Insulator Substrates With Integrated Power Management Circuitry," IEEE Trans. Microwave Theory Techn., vol. 60, no. 6, pp. 1862-1869, Jun. 2012.

[98] R. A. Bianchi, C. Raynaud, F. Blanchet, F. Monsieur, and O. Noblanc, "High voltage devices in advanced CMOS technologies," Custom Integrated Circuits Conference (CICC), pp. 363-370, 2009.

[99] A. W. Ludikhuize, "A review of RESURF technology," International Symposium on Power Semiconductor Devices \& IC's (ISPSD), pp. 1118,2000

[100]L. Vestling, J. Olsson, and K. H. Eklund, "Drift region optimization of lateral RESURF devices," Solid-State Electronics, vol. 46, no. 8, pp. 1177-1184, 2002. 
[101]N. R. Mohapatra, H. Rücker, K. E. Ehwald, R. Sorge, R. Barth, P. Schley, D. Schmidt, and H. E. Wulf, "A Complementary RF-LDMOS Architecture Compatible with $0.13 \mu \mathrm{m}$ CMOS Technology," presented at the International Symposium on Power Semiconductor Devices \& IC's (ISPSD), 2006.

[102]D. Gruner, R. Sorge, O. Bengtsson, A. Al Tanany, and G. Boeck, "Analysis, Design, and Evaluation of LDMOS FETs for RF Power Applications up to $6 \mathrm{GHz}$," IEEE Trans. Microwave Theory Techn., vol. 58, no. 12, pp. 4022-4030, Dec. 2010.

[103]R. Sorge, A. Fischer, A. Mai, P. Schley, J. Schmidt, C. Wipf, T. Mausolf, R. Pliquett, R. Barth, and K. E. Ehwald, "Complementary RF LDMOS module for $12 \mathrm{~V}$ DC/DC converter and $6 \mathrm{GHz}$ power applications," Silicon Monolithic Integrated Circuits in RF Systems (SiRF), pp. 57-60, 2011.

[104]T. Yan, H. Liao, Y. Z. Xiong, R. Zeng, J. Shi, and R. Huang, "CostEffective Integrated RF Power Transistor in 0.18-um CMOS Technology," IEEE Electron Device Letters, vol. 27, no. 10, pp. 856858 , Oct. 2006.

[105]S. Y. Huang, K. M. Chen, G. W. Huang, C. Y. Chang, C. C. Hung, V. Liang, and B. Y. Chen, "Design for Integration of RF Power Transistors in $0.13 \mu \mathrm{m}$ Advanced CMOS Technology," International Microwave Symposium (MTT-S), pp. 323-326, 2007.

[106]M.-C. King, T. Chang, and A. Chin, "RF Power Performance of Asymmetric-LDD MOS Transistor for RF-CMOS SOC Design," IEEE Microw. Wireless Compon. Lett., vol. 17, no. 6, pp. 445-447, Jun. 2007.

[107]J. Sonsky, A. Heringa, J. Perez-Gonzalez, J. Benson, P. Y. Chiang, S. Bardy, and I. Volokhine, "Innovative high voltage transistors for complex HV/RF SoCs in baseline CMOS," International Symposium on VLSI Technology, Systems and Applications (VLSI-TSA), pp. 115-116, 2008.

[108]H. Xiao, L. Zhang, R. Huang, F. Song, D. Wu, H. Liao, W. Wong, and Y. Wang, "A Novel RF LDMOS Fabricated With Standard Foundry Technology," IEEE Electron Device Letters, vol. 30, no. 4, pp. 386-388, Apr. 2009.

[109]A. Mai, H. Rücker, R. Sorge, D. Schmidt, and C. Wipf, "Cost-Effective Integration of RF-LDMOS Transistors in $0.13 \mu \mathrm{m}$ CMOS Technology," presented at the Silicon Monolithic Integrated Circuits in RF Systems (SiRF), 2009.

[110]A. Moscatelli, C. Contiero, P. Galbiati, and C. Raffaglio, "A 12V complementary RF LDMOS technology developed on a $0.18 \mu \mathrm{m}$ CMOS platform," International Symposium on power Semiconductor Devices \& IC's (ISPSD), pp. 37-40, 2004.

[111]Z. Lee, R. Zwingman, J. Zheng, W. Cai, P. Hurwitz, and M. Racanelli, "A Modular 0.18 um Analog/RFCMOS Technology Comprising 32 GHz FT RF-LDMOS and 40V Complementary MOSFET Devices," presented at the Bipolar BiCMOS Circuits and Technology Meeting (BCTM), 2006.

[112]P. Reynaert and M. Steyaert, RF Power Amplifiers for Mobile Communications. Dordrecht, Holland: Springer, 2006, pp. 111-134.

[113]B. Razavi, Design of Analog CMOS Integrated Circuits. New York: McGraw-Hill, 2001, pp. 83-92.

[114]K. H. An, O. Lee, H. Kim, D. H. Lee, J. Han, K. S. Yang, Y. Kim, J. J. Chang, W. Woo, C.-H. Lee, H. Kim, and J. Laskar, "Power-Combining Transformer Techniques for Fully-Integrated CMOS Power Amplifiers," IEEE J. Solid-State Circuits, vol. 43, no. 5, pp. 1064-1075, May 2008.

[115]W. Bakalski, W. Simbürger, H. Knapp, H. D. Wohlmuth, and A. L. Scholtz, "Lumped and distributed lattice-type LC-baluns," International Microwave Symposium Digest (MTT-S), pp. 209-212, 2002.

[116]A. Afsahi and L. E. Larson, "An integrated $33.5 \mathrm{dBm}$ linear $2.4 \mathrm{GHz}$ power amplifier in $65 \mathrm{~nm}$ CMOS for WLAN applications," presented at the Custom Integrated Circuits Conference (CICC), 2010.

[117]P. Haldi, D. Chowdhury, P. Reynaert, G. Liu, and A. M. Niknejad, "A $5.8 \mathrm{GHz} 1 \mathrm{~V}$ Linear Power Amplifier Using a Novel On-Chip Transformer Power Combiner in Standard $90 \mathrm{~nm}$ CMOS," IEEE J. Solid-State Circuits, vol. 43, no. 5, pp. 1054-1063, May 2008

[118]D. Chowdhury, C. D. Hull, O. B. Degani, Y. Wang, and A. M. Niknejad, "A Fully Integrated Dual-Mode Highly Linear 2.4 GHz CMOS Power Amplifier for 4G WiMax Applications," IEEE J. Solid-State Circuits, vol. 44, no. 12, pp. 3393-3402, Dec. 2009.

[119]J. Javidan, M. Atarodi, and H. C. Luong, "High Power Amplifier Based on a Transformer-Type Power Combiner in CMOS Technology," IEEE Trans. Circuits Syst. II, vol. 57, no. 11, pp. 838-842, Nov. 2010.

[120]G. Liu, T.-J. K. Liu, and A. M. Niknejad, "A 1.2V, 2.4GHz Fully Integrated Linear CMOS Power Amplifier with Efficiency
Enhancement," Custom Integrated Circuits Conference (CICC), pp. 141-144, 2006.

[121]G. Liu, P. Haldi, T.-J. K. Liu, and A. M. Niknejad, "Fully Integrated CMOS Power Amplifier With Efficiency Enhancement at Power BackOff," IEEE J. Solid-State Circuits, vol. 43, no. 3, pp. 600-609, Mar. 2008.

[122]K. H. An, Y. Kim, O. Lee, K. S. Yang, H. Kim, W. Woo, J. J. Chang, C.-H. Lee, H. Kim, and J. Laskar, "A Monolithic Voltage-Boosting Parallel-Primary Transformer Structures for Fully Integrated CMOS Power Amplifier Design," Radio Frequency Integrated Circuits Symposium (RFIC), pp. 419-422, 2007.

[123]O. Lee, K. S. Yang, K. H. An, Y. Kim, H. Kim, J. J. Chang, W. Woo, C.-H. Lee, and J. Laskar, "A 1.8-GHz 2-Watt Fully Integrated CMOS Push-Pull Parallel-Combined Power Amplifier Design," Radio Frequency Integrated Circuits Symposium (RFIC), pp. 435-439, 2007.

[124]M. Ruberto, O. B. Degani, S. Wail, A. Tendler, A. Fridman, and G. Goltman, "A reliability-aware RF power amplifier design for CMOS radio chip integration," International Reliability Physics Symposium (IRPS), pp. 536-540, 2008.

[125]G. T. Sasse, F. G. Kuper, and J. Schmitz, "MOSFET Degradation Under RF Stress," IEEE Trans. Electron Devices, vol. 55, no. 11, pp. 31673174, Nov. 2008.

[126]L. Larcher, D. Sanzogni, R. Brama, A. Mazzanti, and F. Svelto, "Oxide breakdown after RF stress: Experimental analysis and effects on power amplifier operation," International Reliability Physics Symposium (IRPS), pp. 283-288, 2006.

[127]J. Fritzin, C. Svensson, and A. Alvandpour, "Design and Analysis of a Class-D Stage With Harmonic Suppression," IEEE Trans. Circuits Syst. $I$, vol. 59, no. 6, pp. 1178-1186, Jun. 2012.

[128]B. Koo, T. Joo, Y. Na, and S. Hong, "A fully integrated dual-mode CMOS power amplifier for WCDMA applications," International SolidState Circuits Conference (ISSCC), pp. 82-84, 2012.

[129]J. Kim, Y. Yoon, H. Kim, K. H. An, W. Kim, H.-W. Kim, C.-H. Lee, and K. T. Kornegay, "A Linear Multi-Mode CMOS Power Amplifier With Discrete Resizing and Concurrent Power Combining Structure," IEEE J. Solid-State Circuits, vol. 46, no. 5, pp. 1034-1048, May 2011

[130]K. H. An, D. H. Lee, O. Lee, H. Kim, J. Han, W. Kim, C.-H. Lee, H. Kim, and J. Laskar, "A 2.4 GHz Fully Integrated Linear CMOS Power Amplifier With Discrete Power Control," IEEE Microw. Wireless Compon. Lett., vol. 19, no. 7, pp. 479-481, Jul. 2009.

[131]A. Afsahi, A. Behzad, and L. E. Larson, "A 65nm CMOS $2.4 \mathrm{GHz} 31.5$ $\mathrm{dBm}$ power amplifier with a distributed LC power-combining network and improved linearization for WLAN applications," International Solid-State Circuits Conference (ISSCC), pp. 452-453, 2010.

[132]N. Wongkomet, L. Tee, and P. R. Gray, "A $+31.5 \mathrm{dBm}$ CMOS RF Doherty Power Amplifier for Wireless Communications," IEEE J. SolidState Circuits, vol. 41, no. 12, pp. 2852-2859, Dec. 2006.

[133]O. B. Degani, F. Cossoy, S. Shahaf, E. Cohen, V. Kravtsov, O. Sendik, D. Chowdhury, C. D. Hull, and S. Ravid, "A 90-nm CMOS Power Amplifier for $802.16 \mathrm{e}$ (WiMAX) Applications," IEEE Trans. Microwave Theory Techn., vol. 58, no. 5, pp. 1431-1437, May 2010.

[134]T. Johansson, O. Bengtsson, S. Lotfi, L. Vestling, H. Norström, J. Olsson, and C. Nyström, "A $+32.8 \mathrm{dBm}$ LDMOS power amplifier for WLAN in $65 \mathrm{~nm}$ CMOS technology," to be presented at the European Microwave Conference (EuMC), 2013.

[135]W. C. Lin, T. C. Wu, Y. H. Tsai, L. J. Du, and Y. C. King, "Reliability Evaluation of Class-E and Class-A Power Amplifiers With Nanoscaled CMOS Technology," IEEE Trans. Electron Devices, vol. 52, no. 7, pp. 1478-1483, Jul. 2005.

[136] V. R. Vathulya, T. Sowlati, and D. M. W. Leenaerts, "Class 1 bluetooth power amplifier with $24 \mathrm{dBm}$ output power and $48 \% \mathrm{PAE}$ at $2.4 \mathrm{GHz}$ in 0.25 um CMOS," Proc. ESSCIRC, pp. 57-60, 2001.

[137]J. Fritzin, T. Sundström, T. Johansson, and A. Alvandpour, "Reliability study of a low-voltage Class-E power amplifier in 130nm CMOS," International Symposium on Circuits and Systems (ISCAS), pp. 19071910,2010

[138]K. Y. Son, C. Park, and S. Hong, "A 1.8-GHz CMOS Power Amplifier Using Stacked nMOS and pMOS Structures for High-Voltage Operation," IEEE Trans. Microwave Theory Techn., vol. 57, no. 11, pp. 2652-2660, Nov. 2009.

[139]R. Zhang, M. Acar, M. P. van der Heijden, M. Apostolidou, L. C. N. de Vreede, and D. M. W. Leenaerts, "A $550-1050 \mathrm{MHz}+30 \mathrm{dBm}$ class-E power amplifier in $65 \mathrm{~nm}$ CMOS," presented at the Radio Frequency Integrated Circuits (RFIC) Symposium, 2011. 
[140]Y. Song, S. Lee, E. Cho, J. Lee, and S. Nam, "A CMOS Class-E Power Amplifier With Voltage Stress Relief and Enhanced Efficiency," IEEE Trans. Microwave Theory Techn., vol. 58, no. 2, pp. 310-317, Feb. 2010.

[141]C. Park, D. H. Lee, Y. Lee, J. Han, S.-H. Baek, Y. Kim, and S. Hong, "1.8-GHz CMOS Power Amplifier with Stage-Convertible Structure Using Differential Line Inductor," Radio Frequency Integrated Circuits Symposium (RFIC), pp. 741-744, 2007.

[142]C. Park, Y. Kim, H. Kim, and S. Hong, "A 1.9-GHz CMOS Power Amplifier Using Three-Port Asymmetric Transmission Line Transformer for a Polar Transmitter," IEEE Trans. Microwave Theory Techn., vol. 55, no. 2, pp. 230-238, Feb. 2007.

[143]D. H. Lee, C. Park, J. Han, Y. Kim, S. Hong, C.-H. Lee, and J. Laskar, "A Load-Shared CMOS Power Amplifier With Efficiency Boosting at Low Power Mode for Polar Transmitters," IEEE Trans. Microwave Theory Techn., vol. 56, no. 7, pp. 1565-1574, Jul. 2008.

[144]H. Lee, C. Park, and S. Hong, "A Quasi-Four-Pair Class-E CMOS RF Power Amplifier With an Integrated Passive Device Transformer," IEEE Trans. Microwave Theory Techn., vol. 57, no. 4, pp. 752-759, Apr. 2009.

[145]Y. Kim, B. H. Ku, C. Park, D. H. Lee, and S. Hong, "A High Dynamic Range CMOS RF Power Amplifier with a Switchable Transformer for Polar Transmitters," Radio Frequency Integrated Circuits Symposium (RFIC), pp. 737-740, 2007.

[146]M. Acar, M. P. van der Heijden, I. Volokhine, M. Apostolidou, J. Sonsky, and J. S. Vromans, "Scalable CMOS power devices with $70 \%$ PAE and 1, 2 and 3.4 Watt output power at 2GHz," Radio Frequency Integrated Circuits Symposium (RFIC), pp. 233-236, 2009.

[147]J. Fritzin, C. Svensson, and A. Alvandpour, "A wideband fully integrated $+30 \mathrm{dBm}$ Class-D outphasing RF PA in 65nm CMOS," International Symposium on Integrated Circuits (ISIC), pp. 25-28, 2011.

[148]W. Tai, H. Xu, A. Ravi, H. Lakdawala, O. Bochobza-Degani, L. R. Carley, and Y. Palaskas, "A Transformer-Combined $31.5 \mathrm{dBm}$ Outphasing Power Amplifier in $45 \mathrm{~nm}$ LP CMOS With Dynamic Power Control for Back-Off Power Efficiency Enhancement," IEEE J. SolidState Circuits, vol. 47, no. 7, pp. 1646-1658, Jul. 2012.

[149]D. Kang, B. Park, C. Zhao, D. Kim, J. Kim, Y. Cho, S. Jin, H. Jin, and B. Kim, "A 34\% PAE, 26-dBm output power envelope-tracking CMOS power amplifier for $10-\mathrm{MHz}$ BW LTE applications," presented at the International Microwave Symposium (MTT-S), 2012.

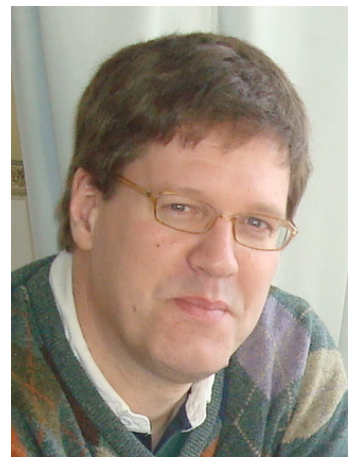

Ted Johansson (M'90-SM'96) was born on September 20, 1959. He received the M.Sc. degree in Applied Physics and Electrical Engineering in 1985, and the Dr. Tech. and Ph.D. degrees in Electronic Devices from Linköping University, Sweden, in 1993 and 1998, respectively.

From 1985 to 1989 , he was with the Swedish Institute of Microwave Technology, Stockholm, conducting research in the area of MOS process technology. He joined Ericsson Components AB, Kista, Sweden, in 1989 and worked with development of RF power transistors for cellular base stations for almost ten years. His interest shifted to SiGe bipolar and BiCMOS RFIC technologies and power amplifiers for wireless handsets. At Infineon Technologies Sweden AB, during 2002-2007, he divided his attention between research on SOI for BiCMOS, technology strategy for future RFIC processes, and competitor technology analysis. In 2005 , the focus again became power amplifiers for wireless applications, mainly for cordless phones. Between 2008 and 2011, he was with Huawei Technologies Sweden $\mathrm{AB}$ as a full-time consultant working on $\mathrm{R} \& \mathrm{D}$ for cellular basestations including integrated PAs, LNAs, future radio architectures, and components technologies. Since 2009, he is Adjunct Professor in the Electronic Devices Group, Linköping University, Sweden. His research interest is mainly CMOS power amplifiers. He has published more than 60 journal and conference papers, one book chapter about $\mathrm{SiGe}$ devices, and holds 40 patents

Dr. Johansson is chairman of the IEEE Sweden Solid-State Circuits/Circuits and Systems Joint Chapter, and vice chairman of the IEEE Sweden Electron Device Chapter.

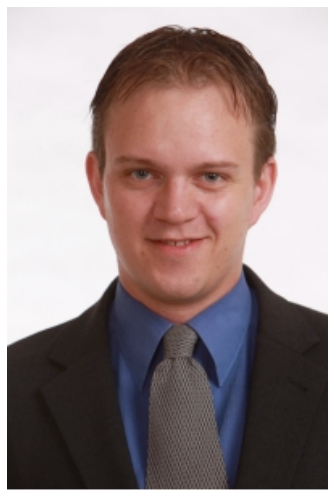

Jonas Fritzin (S'07-M'12) Jonas Fritzin (S'07M'12) received the M.Sc. degree in electrical engineering from Chalmers University of Technology, Göteborg, Sweden, in 2004, and the $\mathrm{Ph} . \mathrm{D}$. degree from Linköping University, Linköping, Sweden, in 2011. Between January 2012 and May 2013 he was with Ericsson AB, Stockholm, Sweden, working on research and development of analog/RF ICs for base stations. Since June 2013 he is with Intel Mobile Communications, Munich, Germany, working as an RF Circuit Design Engineer. His research interests include CMOS RF power amplifiers, transmitters, and predistortion. 